\title{
Um balanço do conceito de capital cultural: contribuições para a pesquisa em educação
}

\author{
Débora C. Piotto ${ }^{1}$ \\ ORCID: 0000-0002-9349-0218 \\ Maria Alice Nogueira ${ }^{2}$ \\ ORCID: 0000-0001-9664-8335
}

\section{Resumo}

0 texto apresenta o artigo "Capital cultural e reprodução escolar: uma revisão crítica”, de autoria de Hugues Draelants e Magali Ballatore, professores da Universidade Católica de Louvain, na Bélgica, traduzido pelas autoras. Seu objetivo é explicitar os motivos pelos quais consideramos importante sua difusão no meio educacional brasileiro. 0 artigo realiza um balanço crítico da contribuição do conceito de capital cultural, com a finalidade de avaliar sua pertinência para a compreensão dos processos contemporâneos de reprodução social por meio da educação escolar. Para isso, seus autores propõem uma discussão sobre a definição do conceito de capital cultural e sobre sua rentabilidade escolar atual. Eles discutem, também, a importância crescente de outros tipos de capital, como o econômico e o social e colocam em relevo a questão de sua conversão em capital cultural. Considerando que tão importante quanto as conclusões às quais Draelants e Ballatore chegaram foi o caminho percorrido até elas, o texto traz alguns destaques do artigo, na intenção não de resumir ou simplificar a riqueza da discussão empreendida, mas, antes, de fazer um convite à sua leitura.

\section{Palavras-chave}

Capital cultural - Desigualdades escolares - Pesquisa educacional.

\section{A review of cultural capital's concept: contributions to educational research}

\section{Abstract}

The text presents the article "Cultural capital and school reproduction: a critical review", by Hugues Draelants and Magali Ballatore, professors at the Catholic University of

1- Universidade de São Paulo, Ribeirão Preto, São Paulo, Brasil. Contato: dcpiotto@usp.br.

2 - Universidade Federal de Minas Gerais, Belo Horizonte, Minas Gerais, Brasil. Contato: malicen@terra.com.br.

(c) (i) (s) https://doi.org/10.1590/S1517-97022021470100302

This content is licensed under a Creative Commons attribution-type BY-NC. 
Louvain, in Belgium, translated by us. Its objective is to explain the reasons why we consider important its diffusion in Brazilian educational environment. The article makes a critical review of the contribution of the cultural capital's concept, in order to assess its relevance for understanding contemporary processes of social reproduction throughout school education. For this, the authors propose a discussion on the definition of the cultural capital's concept and on its current school profitability. They also discuss the growing importance of other capital's types, such as economic and social, and highlight the issue of their conversion into cultural capital. Considering that as important as the conclusions reached by Draelants and Ballatore was the path taken to them, the text brings some highlights of the article with the intention not to summarize or simplify the richness of the discussion undertaken, but instead making an invitation to read it.

\section{Keywords}

Cultural capital - School inequalities - Educational research.

\section{Apresentação}

Nesta breve apresentação do artigo Capital cultural e reprodução escolar: uma revisão crítica, de autoria de Hugues Draelants e Magali Ballatore, professores da Universidade Católica de Louvain na Bélgica, nosso intento é, sobretudo, responder à pergunta: por que nos propusemos a traduzir este texto para a língua portuguesa? Ou, em termos mais precisos, por que consideramos importante sua difusão no meio educacional brasileiro?

Nele, os autores realizam um balanço crítico da contribuição do conceito de capital cultural, com a finalidade de avaliar o seu poder heurístico e a sua pertinência para a compreensão dos processos contemporâneos de reprodução social por meio da educação escolar.

Como se sabe, o conceito de capital cultural foi formulado pelo sociólogo Pierre Bourdieu, no contexto da sociedade francesa de meados dos anos 1960, como uma ferramenta conceitual que pudesse explicar as desigualdades de rendimento escolar verificadas entre os alunos, deslocando o eixo explicativo dos fatores de ordem individual (o "dom", a inteligência, a aptidão, etc.) para os fatores de ordem social, em particular, o meio sociocultural de pertencimento da criança.

Desde seus trabalhos pioneiros realizados em coautoria com Jean-Claude Passeron - Os herdeiros, de 1964, e A reprodução, de $1970^{3}$-, e no decorrer de sua obra, Bourdieu dedicou-se ao debate sobre o peso diferenciado dos fatores econômicos e culturais no destino acadêmico dos estudantes, concluindo pela preponderância que o peso do fator cultural exerce sobre o desempenho escolar. Em artigo publicado em 1966, baseando-se em dados emanados da demografia francesa da época, ele afirmava claramente o papel central desempenhado pela distribuição desigual dos bens culturais entre as classes sociais

3 - As duas obras encontram-se traduzidas no Brasil: BOURDIEU, Pierre; PASSERON, Jean-Claude. Os herdeiros: os estudantes e a cultura. Florianópolis: UFSC, 2014. BOURDIEU, Pierre; PASSERON, Jean-Claude. A reprodução: elementos para uma teoria do sistema de ensino. Rio de Janeiro: Francisco Alves, 1975. 
para as diferenças de rendimento escolar: "com renda igual, a proporção de bons alunos varia de maneira significativa segundo o pai não seja diplomado ou seja bacharel, o que permite concluir que a ação do meio familiar sobre o êxito escolar é quase exclusivamente cultural" (BOURDIEU, 1998, p. 42).

Passados mais de 50 anos, tal afırmação ainda é válida? Diante das transformações econômicas, políticas, sociais, culturais, educacionais ocorridas desde então, ainda se pode afirmar que a dimensão cultural da posição social ocupada é determinante para o rendimento escolar? Ou, colocando a questão nos termos em que Hugues Draelants e Magali Ballatore a formulam: na contemporaneidade, a reprodução social ainda passa pela questão cultural por meio da ação escolar?

Para responder a essas e outras questões correlatas, os autores procedem, no texto, a uma revisão crítica da literatura sociológica de língua francesa. Com base nela, propõem, inicialmente, uma discussão em torno da própria definição do conceito de capital cultural e de como ele vem sendo apropriado por seus diversos utilizadores; e, posteriormente, trazem à luz o debate acerca de sua rentabilidade escolar no momento histórico atual. A essa discussão, os autores acrescentam a importância crescente - para as desigualdades educacionais - de outros tipos de capital, como o econômico e o social, e colocam em relevo a questão de sua conversão em capital cultural.

Considerando que tão importante quanto a chegada é o caminho percorrido, propomonos a trazer aqui alguns destaques do texto, na intenção, não de resumir ou simplificar a riqueza da discussão empreendida, mas antes de fazer um convite à sua leitura.

Os autores começam a discussão acerca do capital cultural debruçando-se sobre dois tipos de definição do conceito, verificados nos trabalhos revisados: uma definição restrita e outra ampla. A primeira restringe a noção de capital cultural às obras culturais ditas legítimas que emanam de e circulam nas diferentes instâncias de legitimação que são as academias, laboratórios, bibliotecas, museus, conservatórios, etc.

Já a segunda definição alarga consideravelmente o conteúdo do conceito, estendendo-o às disposições dos indivíduos e a suas relações com os bens de cultura. E observam que quando se adota a definição restrita de capital cultural, é possível colocar em dúvida seu papel central na explicação das desigualdades escolares atuais; em contrapartida, afırmam que esse não é o caso quando se adota a definição mais ampla, a qual estaria, aliás, segundo eles, em maior conformidade com o próprio pensamento de Bourdieu. Nesse sentido, e mencionando o trabalho do sociólogo da cultura Philippe Coulangeon (2011), Draelants e Ballatore abordam as teses atuais do enfraquecimento da legitimidade e das hierarquias culturais, em favor de certo ecletismo cultural verificado nos indivíduos contemporâneos, argumento de que se servem hoje boa parte dos céticos em relação ao poder explicativo do conceito de capital cultural. Sem discordar dessas teses, Draelants e Ballatore defendem que o capital cultural deve ser compreendido como um processo e não como um atributo dos sujeitos. E citando o trabalho de J-L. Fabiani (2013), defendem que é preciso considerar centralmente a dimensão relacional que Bourdieu sempre atribuiu à sua sociologia da cultura. Assim, segundo os autores, mais importante, na contemporaneidade, seria o modo de se relacionar com o objeto cultural do que o objeto em si mesmo. Dessa forma, em defesa de uma acepção mais alargada do conceito de capital cultural, eles concluem que foram os contéudos culturais 
mais rentáveis na escola contemporânea (a cultura eletrônico-digital, o multiculturalismo, o multilinguismo, etc.) que sofreram mudanças, e não o fenômeno em si de sua maior rentabilidade escolar que beneficia (mais) a uns do que a outros. É nesse sentido que eles insistem na emergência atual de "novas formas de capital cultural".

No bojo dessa discussão, os autores levantam uma questão que consideramos de especial importância para a pesquisa educacional brasileira: o papel da leitura/escrita no sucesso escolar. Ao abordar a questão da eficácia e da transmissibilidade do capital cultural familiar, e com base em um conjunto de pesquisas, eles afirmam que se a alta cultura não ocupa mais o lugar de outrora nos currículos, a socialização escolar, por sua vez, nunca deixou de passar pela escrita e, por isso, a leitura continua a desempenhar papel fundamental no sucesso acadêmico. E eles concluem: mais do que a familiaridade com a cultura legítima, são as práticas de leitura dos estudantes que se revelam escolarmente eficazes na medida em que elas produzem efeitos linguísticos e cognitivos.

Os autores afirmam também que se a cultura considerada legítima dá sua parte de contribuição para a construção do sucesso escolar, não é unicamente por uma razão arbitrária. Ou seja, os conteúdos curriculares transmitidos pela escola não emanam, em sua integralidade, de um "arbitrário cultural”, como acreditava Bourdieu. Essa crítica a ele já havia sido feita na década de 1970, pelo filósofo francês Georges Snyders, que se contrapunha com veemência a esse traço do pensamento bourdieusiano. Segundo Snyders (1976), o fato de as classes dominantes deterem certos conteúdos culturais não seria suficiente para afirmar ser essa a razão deles serem os conteúdos selecionados pela escola como legítimos e dignos de serem transmitidos às futuras gerações. Ao contrário, defende o autor, é por serem epistemologicamente relevantes, em razão de suas características intrínsecas, que esses conteúdos foram valorizados socialmente e apropriados pelos grupos dominantes.

Sem citar o filósofo, Draelants e Ballatore discutem, contudo, resultados de pesquisa que vão nessa mesma direção. Isto é, indicam que, se a cultura tem um papel na reprodução social por meio da escola, não é (unicamente) em razão de sua imposição (a todos) como um arbitrário cultural. Diferentemente, é porque a escolarização produz dispositivos e efeitos cognitivos e comunicacionais que favorecem o êxito acadêmico de certos grupos sociais. No caso específico da leitura, segundo eles, ela contribui para o sucesso escolar na medida em que permite desenvolver competências cognitivas e linguísticas úteis para a aprendizagem em geral.

Assim, de acordo com Draelants e Ballatore, a análise das desigualdades não deve parar na constatação das consonâncias e dissonâncias entre modelos familiares e exigências escolares, fazendo dessas diferenças algo puramente arbitrário. Apoiando-se em Bernard Lahire (1998), os autores afırmam que é preciso explorar as consequências psíquicas da socialização, e sugerem uma volta aos trabalhos de Basil Bernstein a fim de compreender as repercussões cognitivas da socialização linguística. Eles indicam, também, a necessidade de se desenvolver pesquisas que descrevam e analisem processos concretos de transmissão do conhecimento e de produção do fracasso escolar. Apontam, porém, que embora pouco numerosas ${ }^{4}$, essas pesquisas já existem, citando, como exemplo, aquelas realizadas pelo grupo ESCOL (Éducation, Socialisation et Collectivités Locales),

\footnotetext{
4 - É preciso lembrar que os autores referem-se ao contexto francês, uma vez que, no Brasil, essas pesquisas existem e não são em pequeno número.
} 
originalmente composto pelo sociólogo Bernard Charlot, pela linguista Elisabeth Bautier e pelo psicólogo Jean-Yves Rochex, e que ficou conhecido no Brasil pela introdução do conceito de "relação com o saber" (CHARLOT; BAUTIER; ROCHEX, 1992)5.

Por outro lado, Draelants e Ballatore destacam que se Bourdieu sublinhou a importância da relação dos alunos com a cultura a fim de compreender suas eventuais dificuldades escolares, defendeu igualmente que não se pode conceber a produção das desigualdades escolares sem a compreensão do modo de funcionamento da escola e das relações com o saber que essa instituição e seus agentes mantêm.

Essas duas últimas questões - o papel da leitura e do funcionamento escolar no desempenho acadêmico dos estudantes - levam os autores a defender o desenvolvimento de pesquisas no campo, respectivamente, da sociologia do desenvolvimento cognitivo e da sociologia das práticas de ensino.

As pesquisas analisadas criticamente por Draelants e Ballatore, bem como as conclusões a que chegam no que respeita à adequação, pertinência e atualidade do conceito de capital cultural para a compreensão das desigualdades escolares contemporâneas, referem-se, por certo, a um contexto diverso do brasileiro. Todavia, o uso intenso do conceito feito no Brasil, não apenas pela pesquisa sociológica em educação, mas por outros subcampos da pesquisa educacional que busca compreender nosso desigual acesso aos saberes escolares, torna a publicação desse artigo não somente oportuna, mas também necessária.

\section{Referências}

BOURDIEU, Pierre. A escola conservadora: as desigualdades frente à escola e à cultura. In: NOGUEIRA, Maria Alice; CATANI, Afrânio (org.). Escritos de educação. Petrópolis: Vozes, 1998. p. 39-64.

CHARLOT, Bernard; BAUTIER, Élisabeth; ROCHEX, Jean-Yves. École et savoir dans les banlieues... et ailleurs. Paris: Armand Colin, 1992.

COULANGEON, Philippe. Les métamorphoses de la distinction. Paris: Grasset, 2011.

FABIANI, Jean-Louis. Distinction, légitimité e classe sociale. In: COULANGEON, Philippe; DUVAL, Julien (org.). Trente ans après la fistinction. Paris: La Découverte, 2013. p. 69-82.

LAHIRE, Bernard. L'homme pluriel: les ressorts de l'action. Paris: Nathan, 1998.

SNYDERS, Georges. École, classe et lutte des classes. Paris: PUF, 1976.

5 - Com a saída de Bernard Charlot da Universidade Paris VIII, Jean-Yves Rochex passou a coordenar o grupo de pesquisa que, ampliado, tornouse o Centre Interuniversitaire de Recherche "Culture, Éducation, Formation, Travail” (CIRCEFT). 


\title{
Tradução: Capital cultural e reprodução escolar: um balanço crítico'
}

\author{
Hugues Draelants ${ }^{7}$ \\ Magali Ballatore ${ }^{7}$
}

Tradução: Glória M. A. da Silva, Isabela S. Casquer, Débora C. Piotto

Revisão técnica: Maria Alice Nogueira

\section{Resumo}

0 conceito de capital cultural é um dos principais conceitos da sociologia da educação. Em particular, é classicamente usado para explicar as desigualdades escolares e o papel da escola na reprodução social. Mas, ele permanece pertinente ainda hoje? Segundo qual defınição e em quais condições? À luz das profundas transformações que ocorreram nos últimos quarenta anos nas estruturas e funcionamento dos sistemas educacionais, é lícito se colocar essas questões. Este texto propõe, desse modo, uma revisão crítica da contribuição do conceito de capital cultural para a compreensão dos processos atuais de reprodução escolar.

\section{Palavras-chave}

Sociologia da educação - Meio sociocultural - Situação social - Desigualdade social Socialização - Mobilidade estudantil.

\section{Introdução}

Desde as obras fundamentais de Bourdieu e Passeron na França (1964, 1970), os sociólogos da educação consideram que o nível sociocultural é determinante na compreensão das desigualdades educacionais e da reprodução social ${ }^{8}$. A explicação clássica desenvolvida por esses autores sugere, de fato, que as crianças das classes mais altas herdariam de suas famílias vários recursos culturais (linguagem, cultura geral, ferramentas intelectuais, disposições corporais e estéticas, modos de se comportar e falar, gostos refinados...) que se acumulariam e se transformariam, no contexto escolar, em vantagens reais. Isto é possível porque o conteúdo imposto aos alunos e as avaliações escolares fazem parte de uma cultura dita "legítima", isto é, composta por produtos

6- Publicado por Revue Française de Pédagogie, Lyon, 2014.

7- Université Catholique de Louvain. Contatos: hugues.draelants@uclouvain.be; magali.ballatore@uclouvain.be

8- Dentro das teorias que não abordam explicitamente a influência do capital cultural, mas que, implicitamente, apoiam a abordagem "culturebased" para a compreensão do sucesso escolar, podemos enquadrar o trabalho de Basil Bernstein (1975) com seu conceito de códigos de linquacem, restrito e elaborado. 
simbólicos socialmente valorizados (artes, letras, ciências), provenientes dos grupos sociais dominantes que, assim, exerceriam uma forma de violência simbólica sobre os dominados. A própria noção de capital cultural, ausente em "Os Herdeiros” (1964), é introduzida em "A Reprodução" (1970), mas é, especialmente, no livro “A Distinção” (1979a), que Bourdieu desenvolverá a metáfora econômica "capital" para designar as propriedades associadas a esses recursos culturais (transmissão, acumulação e lucros associados).

0 conceito de capital cultural continua a ser, até hoje, um dos principais conceitos da sociologia da educação. Faz parte de uma espécie de fundo comum dos sociólogos da educação francófonos que o utilizam de maneira quase que automática para explicar o papel da escola na reprodução das desigualdades sociais. Mas, vários debates, assim como uma série de desenvolvimentos, induzidos pelas profundas transformações que ocorreram nos últimos quarenta anos nas estruturas e funcionamento dos sistemas educacionais, nos convidam a fazer um retorno crítico sobre esse conceito e a nos perguntarmos: o processo de reprodução social ainda é de natureza essencialmente cultural?

A resposta a essa pergunta depende, particularmente, do que queremos dizer com capital cultural; portanto, começaremos relatando o debate em torno da definição desse conceito, o qual tem sido objeto de compreensões e usos variados. Levantaremos, assim, a questão da rentabilidade escolar do capital cultural. Veremos que ela tende claramente a diminuir, se definirmos o capital cultural de maneira restrita, ou seja, associando-o de modo estreito à cultura "clássica", ela mesma em declínio. Mais do que a familiaridade com a cultura legítima, são as práticas de leitura dos estudantes que acabam sendo academicamente eficazes, na medida em que produzem efeitos linguísticos e cognitivos. Aqueles que optam por uma definição ampla do conceito, por outro lado, argumentam que o capital cultural continua a ser rentável no meio acadêmico. Mas, alguns levantam outra questão essencial, a da sua transmissibilidade, considerada problemática. Outrora apreendido como um atributo, o capital cultural é, agora, percebido mais como um processo; donde a importância de se entender como, na prática, ocorre sua transmissão. Para além das diferenças de definição, as questões sobre a efetividade e a transmissibilidade das vantagens culturais testemunham um desejo de abrir a "caixa preta" do capital cultural, compartilhada por todos os pesquisadores que refletem atualmente sobre este conceito.

Colocaremos ainda a questão da pertinência do capital cultural de forma mais indireta, evocando uma série de novos comportamentos e estratégias distintivos, empregados pelas classes médias e altas de muitos países, que facilitam o sucesso escolar e a integração sócio-ocupacional de seus filhos: a busca de informações sobre orientação, escolha de escola, escolha de percursos, internacionalização de percursos escolares, aulas particulares, coaching... Embora algumas vezes sejam classificadas sob o rótulo de capital cultural (entendido em um sentido amplo), essas novas estratégias destacam o surgimento de novas formas de capital cultural (especialmente o capital internacional) e a crescente importância de outros tipos de capitais (capital econômico e social) na aquisição de capital cultural. Ao fazê-lo, abordaremos a questão da interdependência entre antigas e novas formas de capital cultural e entre espécies de capitais, em particular, por meio da conversibilidade dos capitais econômico e social em capital cultural.

A revisão da literatura apresentada não pretende ser exaustiva, mas, ambiciona destacar os principais debates e as grandes evoluções no modo de abordar e questionar 
o conceito de capital cultural, a fim de avaliar seu poder heurístico para compreender os processos atuais de reprodução social pela escola. Nossa reflexão é menos uma crítica a Bourdieu do que uma crítica à recepção e ao uso de sua teoria da reprodução e do papel que o conceito de capital cultural tem na sociologia da educação. Sendo o pensamento de Bourdieu sobre esse assunto relativamente complexo, nós reintroduziremos aqui, e por várias vezes, certas nuances que foram apagadas na recepção desse pensamento. É de se precisar também que nosso propósito não é o de dizer que os fenômenos culturais estariam totalmente em desuso e seriam inúteis para compreender as desigualdades escolares. Certamente não. Mas, é claro que, no mínimo, seus conteúdos estão se transformando e que o papel desempenhado por esses fenômenos na reprodução social deve ser repensado. Este artigo pretende, portanto, propor uma avaliação crítica da contribuição do conceito de capital cultural para a compreensão dos processos atuais de reprodução escolar.

\section{O debate sobre a extensão da definição: definição restrita versus definição ampla}

A revisão da literatura dedicada à definição do capital cultural evidencia uma primeira defınição, a qual chamaremos de defınição minimalista e a descartaremos de imediato: aquela que associa exclusivamente o capital cultural aos recursos escolares dos pais. De fato, inúmeras pesquisas utilizam o nível de instrução ou o mais alto nível de qualificação dos pais como indicador de capital cultural (ver, por exemplo, THÉLOT; VALLET, 2000), reduzindo, assim, o capital cultural ao que Bourdieu descreve como “capital cultural institucionalizado", em um famoso artigo (BOURDIEU, 1979b).

Lembre-se que, segundo Bourdieu, "o capital cultural pode existir em três formas: no estado incorporado, isto é, na forma de disposições duradouras do organismo; no estado objetivado, na forma de bens culturais, pinturas, livros, dicionários, instrumentos, máquinas, que são o rastro ou a realização de teorias ou críticas a essas teorias, de problemáticas, etc.; e, finalmente, no estado institucionalizado" (BOURDIEU, 1979b, p. 3), um modo de objetivação que se baseia no diploma e que Bourdieu coloca à parte, uma vez que "esse certificado de competência cultural confere a seu portador [...] uma forma de capital cultural que possui relativa autonomia em relação a seu portador e até mesmo em relação ao capital cultural que ele possui em um dado momento histórico" (BOURDIEU, 1979b, p. 5).

0 uso dessa definição minimalista é amplamente determinado pelo tipo de pesquisa, isto é, em pesquisas essencialmente estatísticas, nas quais o capital cultural serve principalmente como uma variável de controle. Por uma questão de economia de modelos estatísticos, a utilização do indicador de capital cultural institucionalizado é justificada, uma vez que a variável "diploma dos pais" detém poder explicativo significativo (VERMANDELE et al., 2012). A nosso ver, o principal interesse dessa definição minimalista, largamente difundida, é que ela atesta o próprio caráter institucionalizado do conceito de capital cultural, que é frequentemente objeto de um uso quase automático na pesquisa educacional e que funciona, assim, como uma "caixa preta".

A revisão da literatura focada em trabalhos explicitamente destinados a discutir o conceito de capital cultural nos leva a distinguir duas outras definições ou mais exatamente 
dois tipos de definições do conceito que iremos agora examinar: uma defınição restrita e uma definição ampla.

\section{A definição restrita de capital cultural}

A defınição restrita de capital cultural tem sido amplamente difundida na sociologia da educação, particularmente no mundo anglo-saxão, onde tem havido uma tendência a assimilá-lo à alta cultura, cultura erudita ou highbrow culture ${ }^{9}$, aquela de grupos de alto status (DIMAGGIO, 1982). Essa é a maneira dominante como o conceito foi recebido na literatura de língua inglesa.

Bourdieu e Passeron têm uma certa responsabilidade no que tange a essa maneira, bastante recorrente entre os sociólogos de língua inglesa, de definir o capital cultural. Com efeito, no livro A reprodução, o capital cultural se refere ao conhecimento e à capacidade de apreciar obras da "cultura erudita". Esse modo de apreender o capital cultural pode ser visto como uma simplificação do pensamento de Bourdieu e uma autonomização indevida do conceito de capital cultural em relação à teoria da reprodução e ao edifício teórico que ele desenvolveu progressivamente, e dentro do qual ele inscreveu o conceito, em conexão com outros conceitos fundamentais, como o de habitus. À luz das produções posteriores de Bourdieu, constatamos, por exemplo, que o aspecto highbrow não é essencial no conceito de capital cultural. De fato, em Bourdieu, a relação com a cultura extrapola a relação com a cultura erudita: além da relação com obras de arte ou do pensamento, ela inclui disposições corporais e estéticas, modos de se portar e de falar, os gostos refinados que se expressam em todas as atividades da vida social, os modos de comer e sentar à mesa, de vestir e de decorar o interior de sua moradia... Mas, é preciso lembrar que a recepção do conceito de capital cultural no mundo anglófono se deu em um momento em que nem todos os trabalhos de Bourdieu haviam sido escritos, nem necessariamente traduzidos. A definição restrita de capital cultural popularizada por DiMaggio é, portanto, em retrospecto e do ponto de vista da ortodoxia bourdieusiana, percebida como reducionista. Robbins (2005), em particular, considera que o uso consistente do conceito de capital cultural passa, doravante, por levar em conta o conjunto da obra de Bourdieu, em vez de se ater à formulação inicial desenvolvida no início de sua carreira. No entanto, podese considerar perfeitamente legítimo que um conceito viaje e evolua num determinado momento. Como o próprio DiMaggio (2007) argumentou, respondendo a uma crítica desta ordem formulada por Goldthorpe (2007), emprestar de um autor uma terminologia ou um de seus conceitos não implica que se deva prestar juramento de lealdade, nem adotar a totalidade de sua teoria.

Assim, essa definição de capital cultural é propositalmente restrita porque é importante para seus representantes, majoritariamente quantitativistas, tornar o conceito operacional (DIMAGGIO, 2007). É por isso que Goldthorpe (2007) ironicamente descreve esse tipo de recepção do conceito de capital cultural como uma tentativa de domesticação de Bourdieu ${ }^{10}$.

\footnotetext{
9 - Alta cultura (em inglês no original). Nota das Tradutoras (NT).

10- Mas, Goldthorpe (2007) critica com a mesma aspereza a definição ampla de capital cultural que será abordada mais à frente. Ele a qualifica como uma definição selvagem ("Bourdieu wild" versus "Bourdieu domesticated"), deixando indomada essa fera sociológica que é Bourdieu. Para ele, adotar 0 conceito de capital cultural equivaleria a renunciar ao rigor ou à originalidade, independentemente da definição usada. Assim, ele
} 
Com efeito, os defensores da definição restrita apreendem o capital cultural a partir de uma série de perguntas simples, por exemplo, sobre a frequência a museus, teatros e concertos de música clássica, a prática das artes plásticas, o número de livros lidos no último mês ou durante o ano... Ao combinar as respostas a várias questões desse tipo, os pesquisadores constroem um índice sintético do conceito de capital cultural que, geralmente, assume a forma de uma pontuação ou uma escala. Essa transformação do conceito em variável é, evidentemente, um procedimento muito clássico na metodologia de pesquisas por questionários, especialmente quando se trata de operacionalizar noções abstratas.

No entanto, não é uma questão isenta de problemas porque, além do fato de que esses indicadores variam muito de uma pesquisa para outra (algumas poderão incluir atividades culturais que não são necessariamente parte da cultura erudita, como a frequência ao cinema ou ao zoológico), as diferenças na frequência de uma determinada prática escondem diferenças qualitativas potencialmente mais influentes (o que eu leio e/ou assisto? Com qual olhar?). Todas essas sutilezas são, obviamente, difíceis de considerar em estudos estatísticos, onde o essencial é garantir que o capital cultural seja conceitualmente diferenciado dos efeitos das aptidões dos alunos, por meio de métodos de análise de regressão múltipla. A esse respeito, haveria outra "traição" em relação ao trabalho de Bourdieu. Este autor, de fato, considera o capital cultural inextricavelmente ligado às aptidões e ao desempenho escolares, razão pela qual ele rejeita a pertinência do raciocínio do tipo "todo o mais é constante", naquilo que os concerne ${ }^{11}$. Ao invés de métodos de tratamento estatístico que desconhecem as relações de interdependência entre "variáveis" ou "fatores" dos quais se busca isolar o "peso" ou "efeito", Bourdieu prefere outros métodos de análise multivariada, em particular, a análise fatorial de correspondência que ele empregou em muitas pesquisas.

\section{A definição ampla de capital cultural}

A definição ampla do conceito de capital cultural, dominante no trabalho dos sociólogos franceses, também fica evidente nos escritos de um certo número de sociólogos americanos e britânicos, entre os quais podemos mencionar, particularmente, Lamont e Lareau (1988), McDonough (1997) e Reay (2004). Essa definição é mais difícil de ser descrita em poucas palavras. Nela, o capital cultural se refere a uma variedade de práticas

considera o trabalho de Bourdieu como relativamente rigoroso em sua acepção domesticada, mas pouco original; e inversamente ele 0 julga original em sua acepção selvagem, em particular sua teoria da reprodução, percebida como insuficientemente rigorosa. Segundo ele, seria possível dispensar o conceito de capital cultural, e simplesmente falarmos de "recursos culturais".

11- 0 argumento é discutível. De acordo com os defensores da análise de regressão, justifica-se o uso desse tipo de análise multivariada: "Bourdieu parece rejeitar a análise multivariada [regressão], com base em que todos os elementos de reprodução de classe estão interligados [...] mas inferir do fato de que estamos lidando com um sistema de fatores inter-relacionados que não podemos isolar a influência de fatores particulares é claramente falacioso. [...] ao invés de ser uma razão para rejeitar a análise de regressão multivariada, esta é precisamente a razão pela qual tais análises são essenciais. A análise multivariada [de regressão] só seria descartada se as variáveis não fossem apenas associadas, mas completamente confundidas" (ZIMDARS; SULLIVAN; HEATH, 2009, p. 651). As técnicas de regressão múltipla são também criticadas por seu caráter artificial. 0 raciocínio quase experimental que as fundamenta e se manifesta através da cláusula "todo o mais é constante", afasta, por vezes, consideravelmente das configurações reais do mundo social e contém o risco de interrogações absurdas (PASSERON, 1991, 1997). As técnicas de regressão devem, portanto, ser usadas com cautela; mas, isso não justifica, aos olhos dos especialistas, sua rejeição categórica. Depois de analisar detalhadamente as reservas feitas contra elas, Vallet conclui que "é possível usar a análise de regressão em uma descrição sofisticada na qual o modelo serve para resumir as características fundamentais dos dados sem distorcê-los significativamente" (NALLET, 2007, p. 6). 
de educação parentais (LAREAU; WEININGER, 2003). Essa abordagem enfatiza a natureza socialmente determinada do capital cultural: ele está associado às normas educativas das classes sociais capazes de impor os critérios de avaliação mais favoráveis aos seus filhos: "o aspecto crítico do capital cultural é que ele permite que a cultura possa ser usada como um recurso que dá acesso a vantagens, está sujeito a monopolização, e, sob certas condições, pode ser transmitido de uma geração a outra" (ver LAREAU; WEININGER, 2003, p. 587) ${ }^{12}$.

Ao contrário da definição restrita centrada no conteúdo do capital cultural, que o iguala à cultura consagrada, à dos grupos de status elevado, a definição ampla enfatiza mais o efeito do capital cultural, particularmente seu papel na escola e na reprodução social. Um dos méritos dessa definição alternativa é, portanto, sugerir uma distinção entre o efeito e o conteúdo do capital cultural: a cultura highbrow estando em declínio, como veremos mais adiante, é pertinente nos interrogamos sobre o aparecimento de novos conteúdos culturais porque, de acordo com os defensores da definição ampla, qualquer competência pode funcionar como capital cultural. Ao fazer isso, a definição ampla, diferentemente da defınição restrita, se mostra mais respeitosa e mais conforme à defınição de Bourdieu. Na obra dele, o capital cultural não pode efetivamente ser reduzido a uma definição de diferentes "culturas" (legítimas, comuns, escolares), como meros repertórios de obras ou de produções culturais, notadamente porque o capital cultural deriva de uma definição relacional e, portanto, em movimento (FABIANI, 2007).

A principal limitação dessa definição alternativa é seu caráter extremamente amplo. Um conceito necessariamente perde em compreensão o que ganha em extensão. A definição ampla tende a transformar o conceito de capital cultural em um "depósito", no qual se pode acomodar toda uma gama de mecanismos, processos e realidades diversas e variadas. Esse conceito também funciona potencialmente como um conceito "para-sol" que nos impede de ver o que está mudando e o que há de novo nos processos de reprodução social pela escola (DRAELANTS, 2014). Isso também tem consequências metodológicas em termos de operacionalização (KINGSTON, 2001; NOGUEIRA, 2008). A dimensão relativamente abstrata da concepção ampla de capital cultural torna seu uso complexo no contexto de uma pesquisa quantitativa. Portanto, não é de surpreender que os promotores de tal definição sejam geralmente pesquisadores que privilegiam abordagens qualitativas ou mesmo etnográficas. No contexto do debate sobre o capital cultural, pode-se dizer, portanto, que a oposição definição restrita/defınição ampla coincide com a oposição quantitativa/qualitativa, mesmo que isso não seja uma fatalidade.

\section{Reprodução social e capital cultural: a rentabilidade escolar do capital cultural em declínio?}

Como dissemos na introdução, a questão central deste artigo é a de questionar se a reprodução social por meio da escola ainda é, principalmente, de natureza cultural. 0 debate sobre a definição do conceito de capital cultural que acabamos de evocar afeta diretamente a resposta a essa questão.

12 - Traduzido do original em inglês «the critical aspect of cultural capital is that it allows culture to be used as a resource that provides access to scarce rewards, is subject to monopolization, and, under certain conditions, may be transmitted from one generation to the nexts (ver LAREAU; WEININGER, 2003, p. 587). (NT). 


\section{Argumentos apresentados em apoio à tese do declínio}

Os pesquisadores que adotam uma definição restrita de capital cultural (que o associa à highbrow culture) geralmente acreditam que o capital cultural desempenha um papel menor, hoje, na reprodução social (ver, por exemplo, KINGSTON, 2001; GRIPSRUD; HODVEN; MOE, 2011). Em apoio a essa última tese, podemos invocar a crítica dirigida à teoria da reprodução social por alguns pesquisadores que adotam uma abordagem na intersecção da história e da sociologia da educação, com o objetivo de colocar as teorias sociológicas à prova dos fatos históricos (PETITAT, 1971, 1982). Sendo a análise de Bourdieu e Passeron historicamente situada, sua validade deve ser apreciada em relação a isso e não pode ser generalizada para além ou aquém desse período preciso.

A história da educação nos ensina que a escola nem sempre desempenhou um papel central no processo de hierarquização dos grupos sociais. É relativamente recente que a escola assumiu um papel preponderante na legitimação de posições sociais. Bourdieu não ignorou isso. Em alguns de seus trabalhos, ele mostra, aliás, que a reprodução social nem sempre passou pela escola (JOURDAIN; NAULIN, 2011). Nas sociedades pré-capitalistas estudadas pelo jovem etnólogo Bourdieu, como a sociedade cabila, ou sua terra natal, o Béarn, dominam as estratégias matrimoniais de reprodução social. Mesmo em nossas sociedades modernas avançadas, a família mantém um papel proeminente na reprodução social, especialmente via transmissão cultural doméstica.

Passeron reconheceu explicitamente a relevância da crítica sócio-histórica, deixando subentendido que isso era óbvio para Bourdieu e para si mesmo. No livro $O$ raciocínio sociológico, ele especifica que a tese da reprodução é "historicamente falsa" se pensarmos que ela descreve uma realidade trans-histórica. Segundo ele, o livro descrevia apenas "a ‘idade de ouro’ da escola burguesa (na França, final do século XIX e primeira metade do século XX), isto é, no momento 'orgânico' em que a ilusão da meritocracia escolar teve sua plena performance social e simbólica.” (PASSERON, 1991, p. 173).

E quanto à validade da teoria da reprodução hoje? Antes de chegarmos à descrição da situação atual, paremos por um momento para dar uma olhada naquilo que, à época das obras Os herdeiros e $A$ reprodução, permitiu explicar a rentabilidade escolar do capital cultural.

A priori, o capital cultural explica tanto melhor as desigualdades escolares, quanto mais exista uma "cultura legítima" claramente identificável, que permita aos indivíduos que possuem esse capital cultural formal se distinguirem. Existem dois postulados subjacentes à tese inicial de Bourdieu e Passeron: 1) há uma cultura legítima dominante (claramente separada da cultura comum); 2) A cultura escolar emana da cultura legítima (e a transmite). Esses dois postulados - que constituem a condição de possibilidade para que o capital cultural seja rentável - nos parecem questionáveis no contexto atual. Não é evidente que eles ainda sejam defensáveis dessa forma.

Em primeiro lugar, podemos dizer que ainda existe uma cultura legítima e dominante (no sentido de um consenso social relativo sobre uma hierarquia cultural) ${ }^{13}$ claramente

13 - Como explica Bernard Lahire, sociologicamente, a noção de cultura legítima é fundamentalmente uma questão de crença e dominação: "Temos o direito de falar de legitimidade cultural se, e somente se, um indivíduo, grupo ou a comunidade acredita na importância e, muitas vezes, na superioridade de certas atividades e bens culturais em detrimento de outros. E [esta] crença só chega a se instaurar [...] porque alguns produtos e atividades culturais dispõem de meios poderosos de impor sua legitimidade (a Escola sendo central, já que é a única, através da escolaridade obrigatória 
separada da cultura comum? A sociologia da cultura parece caracterizar a era atual como a do enfraquecimento da clivagem tradicional entre cultura erudita e cultura popular: as produções da cultura acadêmica seriam, desde a década de 1960, cada vez menos distinguíveis daquelas da cultura popular ou da cultura de massa. As hierarquias culturais estabelecidas por Bourdieu no livro A distinção têm inegavelmente um caráter datado. Desde então, a clivagem não mais oporia elite e massa, mas as figuras do "onívoro" e do "unívoro": o onívoro é caracterizado pelo ecletismo e exotismo de seus gostos e práticas culturais, sendo o universo cultural do unívoro claramente mais limitado e estreito (PETERSON, 1992; DONNAT, 1994).

A observação do enfraquecimento das hierarquias e legitimidades evidenciada pelo desenvolvimento de um certo ecletismo cultural não significa, entretanto, que não há mais associação entre origem social e preferências culturais nem fenômenos de distinção (COULANGEON, 2011). A própria existência da norma da legitimidade não estaria em questão, somente seu conteúdo estaria se recompondo. "Toda forma cultural é suscetível de banalização ou enobrecimento, esquecimento ou redescoberta” (FABIANI, 2013, p. 79). Em outras palavras, aqui, novamente, devemos "levar a sério a dimensão relacional que Bourdieu atribui à sua sociologia da cultura” (FABIANI, 2013, p. 79). Acrescentemos que a maior parte do tempo o ecletismo não é exercido sem limites, "se os membros das categorias sociais mais altas expressam uma gama de gostos que são consideravelmente mais amplos e diversificados do que os das outras categorias, indo além dos gêneros eruditos, eles também manifestam uma distância bastante pronunciada com respeito a [certos] gêneros" (a música rap ou reality shows, por exemplo, são ativamente rejeitados pelas classes altas) (COULANGEON, 2011, p. 123-124). Por outro lado, quando os membros das classes superiores se permitem consumir formas culturais pouco legítimas, não é necessariamente com o mesmo olhar nem com a mesma relação a essas práticas. Como salienta Lahire, não devemos perder de vista que "os consumidores não se apropriam jamais indiferentemente de produtos pertencentes a diferentes registros culturais” (LAHIRE, 2004, p. 257-258). Nesse sentido, o modo de relação com a cultura (reflexiva e distanciada) pode ser mais importante para as dinâmicas de distinção social do que a escolha precisa de objetos culturais (PRIEUR; SAVAGE, 2013).

0 declínio relativo da cultura legítima não significaria então que a cultura não seria mais tão classificadora, mas, continuaria ainda desempenhando um papel determinante na produção de desigualdades escolares? Temos todos os motivos para acreditar que a afınidade entre cultura escolar e cultura legítima não é mais tão clara quanto antes, o que pode ser constatado através da transformação das hierarquias disciplinares, notadamente o declínio das Ciências Humanas, cuja feminização e relativa democratização do acesso (ao

\footnotetext{
e de seu sistema de avaliação-sanção dos produtos de sua inculcação, a dispor de um público cativo)" (LAHIRE, 2004, p. 39). Lahire também afirma que em nossas sociedades "há duas grandes maneiras de dominar a cultura: dominar pelo número e pela popularidade (por exemplo, canções, séries de televisão, programas de entretenimento de rádio ou televisão, best sellers, etc.), e dominar pela raridade e nobreza (por exemplo, obras musicais, pictóricas, literárias, teatrais, etc.). [...] Esses dois tipos principais de cultura são mantidos por canais de transmissão e órgãos legitimadores, que são, em grande parte, distintos, mas às vezes também comuns: canais de televisão grande público [...], as rádios mais populares, cinemas e algumas revistas, por um lado; a Escola, o Estado, a academia, os conservatórios, museus, bibliotecas, [...] mas, também parte de programas de TV e rádio, cinemas, revistas, por outro" (LAHIRE, 2004, p. 63). "De qualquer forma, é impossível agir como se estivéssemos lidando com um espaço cultural homogêneo do ponto de vista da legitimidade, isto é, estruturado através de uma única oposição legítima/ilegítima; oposição que todos conheceriam e praticariam, à qual todos dariam o mesmo significado e na qual todos acreditariam com a mesma intensidade" (LAHIRE, 2004, p. 65).
} 
contrário dos ramos científicos) podem ser vistos como indicadores de sua desvalorização social ${ }^{14}$. Em outras palavras, também na escola, a cultura clássica está se tornando cada vez mais marginal considerando as mudanças curriculares, já que os currículos valorizam a cultura científica e técnica mais do que no passado (JACQUET-FRANCILLON, 2008).

Além disso, a escola não é mais uma fortaleza que construiria uma muralha da China entre ela e o mundo cultural dos adolescentes. 0 fenômeno da massificação escolar permitiu que gerações de jovens desenvolvessem uma relação escolar com a cultura; mas, ao mesmo tempo, abrindo a escola para todas as categorias sociais, ele trouxe a cultura popular para dentro da escola. A escola não é mais um "santuário" (DUBET, 2002), um espaço culturalmente isolado do resto da sociedade. Salvo em algumas escolas secundárias de elite dos grandes centros urbanos (ver SIROUX, 2011) e em algumas instituições de ensino superior de alto prestígio, os herdeiros (no sentido de Bourdieu e Passeron) estão diluídos na massa dos estudantes. Sua marginalização não é apenas quantitativa, mas também cultural e identitária. Eles são, de fato, obrigados a desativar qualquer indício de alta cultura se não quiserem ser condenados ao ostracismo por seus pares e revestidos de qualificativos pouco lisonjeiros ("nerd", "bobo da corte", etc.). Em suma, como explica Pasquier (2005), podemos estimar que a escola perdeu boa parte de sua capacidade de agir como instância de legitimação cultural em proveito da indústria cultural, de um lado, e do grupo de pares, de outro ${ }^{15}$.

Em outras palavras, dois grandes fenômenos sociais colocam em questão a tese de um vínculo direto entre cultura escolar e cultura consagrada: por um lado, o nascimento de um novo sistema de distinção em que as desigualdades sociais de acesso à cultura desempenham um papel inferior e, por outro, a massificação escolar com o que ela implica em termos de recomposição curricular e entrada da cultura juvenil na escola. Em suma, se ainda existe uma crença socialmente compartilhada em uma cultura legítima, de qualquer forma, esta não é mais (tão) dominante como era no passado. A escola é hoje tanto, ou ainda mais, um lugar de difusão da indústria cultural através das relações com os pares, do que um meio de impor a cultura legítima outrora dominante.

A contribuição da sociologia das práticas de ensino também poderia ser resumida em apoio à tese do declínio da rentabilidade escolar do capital cultural. Se Bourdieu e Passeron enfatizaram claramente a importância da relação dos estudantes com a cultura, a fim de identificar suas possíveis dificuldades na escola, eles também enfatizaram que é impossivel explicar a produção de desigualdades educacionais sem questionar, em contrapartida, o modo de funcionamento da escola e as relações com o saber próprias da instituição e de seus agentes. Como o professor desempenha um papel de transmissor e intermediário entre a cultura escolar e o aluno, a sua relação com a cultura é uma questão pedagógica importante (ZAKHARTCHOUK, 1999). A distância cultural entre um professor e um aluno determina sua intercompreensão e pode reduzir ou, pelo contrário, reforçar a distância entre a cultura do aluno e a cultura escolar. Desde os trabalhos de Berger (1979),

14 - No entanto, isso não diminui a importância da dimensão cognitiva, linguística e das práticas de leitura do capital cultural, como se verá mais à frente.

15- Isso não significa que o papel social e econômico da escola tenha diminuído. Pelo contrário, foi reforçado, dado o peso determinante do desempenho escolar para a inserção e o sucesso profissional. 
depois os de Thélot (1994) e mais recentemente de Charles e Cibois (2010), sabemos que a composição social do corpo docente mudou: a origem social dos professores tende, desde os anos 1960, para um recrutamento desse corpo profissional nos estratos médios da população ${ }^{16}$. Esta evolução é, sem dúvida, acompanhada por uma mudança na relação com a cultura não apenas por causa desse pertencimento social às classes médias, mas também, e talvez mais importante, em razão do desenvolvimento de um novo modelo de profissionalidade. De fato, espera-se que o atual professor seja um bom pedagogo, um "praticante reflexivo", mais do que um "professor educado", altamente culto, detentor de um saber disciplinar (MAROY, 2001).

A este respeito, em conexão com uma preocupação pedagógica com a busca pelo interesse do aluno, há uma crescente abertura dos professores para a cultura jovem. Eloy distingue duas estratégias de uso da cultura juvenil pelos professores: a estratégia de estetização do popular e a estratégia de popularização do cientista. A primeira consiste em se servir de conteúdos julgados próximos da cultura dos alunos como um dos principais objetivos do ensino. Por exemplo, essa abordagem sustenta a exploração de formas literárias consideradas familiares aos estudantes, como histórias em quadrinhos ou literatura infantil popular (Crepúsculo, Harry Potter) por alguns professores franceses (DAGIRAL; TESSIER, 2010). A segunda consiste em transmitir repertórios eruditos por meio de escalas de apreciação popular, a fim de "torná-los populares" junto aos alunos. No contexto de uma aula de música, o professor explicará aos alunos, por exemplo, as ideias que inspiraram ou que quis passar o compositor da música clássica ouvida em classe. "Ao fazê-lo, os alunos podem trazer a obra de volta ao seu próprio mundo, a suas próprias experiências, representações e preocupações” (ELOY, 2010) ${ }^{17}$.

\section{Contra a tese do declínio: o argumento da definição flexível}

Por todas as razões que acabamos de revisar, parece que o capital cultural passa a desempenhar um papel diferente na (re)produção de desigualdades escolares, a menos que seja definido de forma restrita, i.e., a partir de práticas culturais consagradas. Com efeito, os proponentes de uma definição ampla de capital cultural (para a qual o capital cultural não se limita à alta cultura) consideram que é muito fácil dizer que o capital cultural não explica mais a reprodução social se se fizer uma leitura restrita que iguala o capital cultural à cultura erudita:

É bastante óbvio que as formas de highbrow culture que Bourdieu detectou como funcionando como capital cultural na França nas décadas de 1960 e 1970 não gozam do mesmo reconhecimento social 30-40 anos depois, nem na França nem em outros países. (PRIEUR; SAVAGE, 2013, p. 249).

\footnotetext{
16 - Com tendências divergentes de acordo com os níveis de escolaridade: maior seletividade social dos professores de ensino primário, menor seletividade social dos professores do ensino secundário (VALLET; DEGENNE, 2000).

17- 0 trabalho de Eloy, que reivindica explicitamente para si uma herança bourdieusiana, mostra que as evoluções dos currículos e das práticas no ensino de música rompem apenas superficialmente com as pressões da forma escolar, contribuindo assim para a renovação (mas não para 0 enfraquecimento) do caráter socialmente implícito dos modos de trabalho pedagógico e da dominação das formas de "cultura legítima" (ver, em especial, ELOY; PALHETA, 2008).
} 
Os defensores de uma definição ampla de capital cultural, mais "compatível com Bourdieu", tenderão a responder negativamente à questão do declínio da rentabilidade escolar do capital cultural, considerando que ainda existe uma cultura legítima e dominante, mas que evolui em seu conteúdo, como muda a cultura escolar. Prieur e Savage, entre outros, opõem-se claramente à tendência de reificar o conceito e defendem uma abordagem flexível do capital cultural, distinguindo entre capital cultural absoluto (ou fixo) e capital cultural relativo (ou flutuante) ${ }^{18}$.

A ideia chave aqui é que as competências que funcionam como capital cultural evoluem. Nesse sentido, não podemos falar de um declínio da rentabilidade do capital cultural. 0 capital cultural continua a ser rentável, produz sempre efeitos benéficos para os seus detentores: há sempre práticas culturais parentais mais em conformidade com as dos professores e da cultura escolar em geral, só que não estamos falando exatamente da mesma coisa que na década de 1960; não são mais as mesmas práticas que designamos sob o vocábulo de capital cultural. Como desenvolveremos adiante, o capital cultural é hoje enriquecido pelo domínio de idiomas e linguagens (especialmente digitais) e técnicas circulatórias.

\section{Eficácia e transmissibilidade do capital cultural: a abertura da "caixa preta"}

Para além da questão da rentabilidade do capital cultural, compreender em que medida o capital cultural permanece relevante para entender a reprodução social pela escola implica questionar os mecanismos e processos subjacentes à eficácia e à transmissibilidade do capital cultural. Em outras palavras, trata-se de abrir a "caixa preta" do capital cultural, a fim de compreender, ao mesmo tempo, tanto o princípio de sua efetividade quanto o de suas condições de transmissibilidade. Nos últimos quinze anos, tanto os proponentes de uma definição de capital cultural como cultura cultivada, quanto os de uma definição de capital cultural como um conjunto de práticas educativas, começaram este trabalho. Como detalharemos abaixo, o esforço de pesquisa vai em duas direções diferentes e complementares: por um lado, trata-se de identificar por onde passa concretamente o efeito do capital cultural sobre o sucesso escolar e, por outro, de entender como, na prática, ocorre a transmissão cultural. Esse duplo questionamento nos parece ainda mais fundamental para entender a atual reprodução social do que o questionamento anterior sobre a rentabilidade do capital cultural, cuja resolução, como vimos, depende essencialmente da definição de capital cultural adotada e tende, assim, a se tornar um debate improdutivo "por" ou "contra" a interpretação bourdieusiana do conceito.

\section{Do capital cultural ao capital linguístico e cognitivo}

A preocupação com a abertura da caixa-preta do capital cultural, embora transversal ao debate sobre a definição do conceito, difere, no entanto, conforme o tipo de definição de capital cultural adotado. Os defensores da definição restrita visam principalmente

18 - Pode-se objetar, no entanto, que tal argumento é bastante conveniente, na medida em que o conceito de capital cultural opera em um nível muito alto de generalidade, o que constitui, em essência, a crítica feita por Goldthorpe (2007). 
a compreender, acima de tudo, o que é importante no capital cultural e produz impacto significativo sobre o sucesso escolar. Eles concentram, então, suas investigações nos efeitos comparativos de diferentes práticas consagradas: alguns perguntam, por exemplo, se é mais eficaz educacionalmente frequentar regularmente o teatro ou ser um grande leitor? (ver DE GRAAF, DE GRAAF; KRAAYKAMP, 2000; bem como SULLIVAN, 2001); outros estão interessados na rentabilidade de novas práticas culturais (televisão, videogames, etc., ver, em particular, PAINO; RENZULLI, 2013), levando em conta o declínio da cultura consagrada acima mencionado. Em termos metodológicos, a contribuição de análises estatísticas multivariadas deve ser enfatizada aqui. Para explicar como o capital cultural é reconvertido em vantagem escolar, trata-se de estabelecer uma relação estatística entre as várias práticas culturais e o desenvolvimento de conhecimentos e competências linguísticas e cognitivas, tendo por hipótese que as práticas culturais são desigualmente produtivas.

Isto é particularmente demonstrado pelo trabalho de uma equipe de pesquisadores holandeses (DE GRAAF, DE GRAAF; KRAAYKAMP, 2000) que visa a isolar os efeitos específicos sobre o sucesso escolar de várias atividades tradicionalmente incluídas na definição highbrow de capital cultural. De Graaf e seus colegas realmente consideram dois aspectos distintos do capital cultural parental: o "interesse pela arte" (participation in beaux arts) e as "condutas em matéria de leitura" (reading behavior). Todo o mais sendo constante, fica evidente que ser educado em um ambiente familiar onde a leitura desempenha um papel importante é significativamente mais eficaz em termos de sucesso escolar do que ter pais que frequentem o teatro e a ópera, visitem os museus, galerias e vernissages. Os autores associam essa diferença ao fato de que tais atividades, aqui incluídas como "a prática das belas artes", referem-se a formas culturais menos relacionadas à escrita e às competências linguísticas ${ }^{19}$. Em outras palavras, de acordo com esses autores, a definição highbrown de capital cultural mistura atividades culturais de vários tipos, algumas das quais têm pouco a ver com o domínio dos códigos culturais que realmente importam no ambiente escolar, a saber, competências cognitivas, analíticas, escriturais e linguísticas que a leitura assídua permite desenvolver.

Para explicar seus resultados, De Graaf e sua equipe formulam também a hipótese de que os aspectos relevantes do capital cultural podem variar de um sistema educacional para outro. Nos Países Baixos, a prática das artes plásticas não teria um papel na produção das desigualdades escolares, uma vez que o currículo nesse país dá pouca ênfase, ao contrário da França, a temas como a história ou a filosofia que tradicionalmente apelam à cultura legítima e ao interesse pela arte. Parece-nos importante acrescentar, como vimos, que, se a cultura legítima já não ocupa o mesmo lugar que nos currículos do passado, a socialização escolar, em contrapartida, passa sempre em primeiro lugar pela palavra escrita, razão pela qual a leitura continua a desempenhar um papel fundamental no sucesso do aluno.

Pesquisa conduzida por Sullivan (2001), embora amplamente alinhada com os resultados da equipe holandesa, trouxe importantes nuances no que se refere aos componentes relevantes do capital cultural. Sullivan operacionalizou o conceito de capital

19 - 0 interesse pela arte seria, acima de tudo, uma forma de demonstrar um pertencimento social, proporcionando assim um benefício em termos de distinção social. Poder-se-ia, no entanto, argumentar que 0 interesse pela arte também pode contribuir para 0 desenvolvimento de competências e conhecimentos, mesmo que apenas em termos de disposições estéticas, valorizadas no contexto específico da educação artística. 
cultural testando dois outros tipos de atividades, além da leitura e do interesse geral pela arte, entre jovens de 16 anos. Por um lado, a prática de um instrumento ou a escuta de música clássica que se revelou, assim como o interesse pela arte, sem qualquer efeito no desenvolvimento das capacidades linguísticas e do conhecimento cultural. Por outro lado, a pesquisa abordou os hábitos televisivos e o tipo de programas assistidos, categorizandoos de acordo com seu conteúdo cultural. Sullivan mostra que a televisão, apesar de ser uma mídia emblemática da cultura popular, compartilha com o livro a capacidade de promover o sucesso escolar, pois facilita, por meio de certos programas (factuais como os documentários ou suficientemente sofisticados em termos de vocabulário e referências culturais), o desenvolvimento de capacidades linguísticas e de conhecimentos culturais. Como aponta Sullivan, pode-se questionar o sentido da relação: ler ou assistir a programas de televisão sofisticados contribui para o desenvolvimento da inteligência, ou os hábitos de leitura e de televisão dos estudantes simplesmente refletem o nível de desenvolvimento intelectual anterior dos alunos? Os resultados não nos permitem decidir. É provável que a relação atue em ambas as direções.

Uma sociologia do desenvolvimento cognitivo que estudasse, em particular, como a socialização torna as crianças capazes de pensar de uma maneira ou de outra, seria útil para aprofundar esses resultados; é o que alguns sociólogos desejariam ardentemente (ver em especial DURU-BELLAT, 2007). A análise não pode, de fato, parar na constatação de consonâncias e dissonâncias entre modelos familiares e exigências escolares; e estabelecer como o faz Bourdieu, que as diferenças são puramente arbitrárias. Trata-se, hoje, de explorar as consequências psíquicas da socialização (LAHIRE, 1998) que, em particular, envolve a reconexão com o trabalho de Bernstein, a fim de compreender como a socialização linguística tem repercussões cognitivas. Ao fazer isso, Nash sugere que, por meio de interações verbais, as crianças realmente desenvolvem "o saber-fazer no processamento de informações simbólicas, especialmente aquelas formas de competência 'verbal analógica' que o próprio Bernstein observou como características dos professores de classe média, que poderiam ser consideradas como constituindo um habitus cognitivo específico" (NASH, 2007, p. 161).

Ir mais longe incluiria integrar a contribuição das pesquisas que se ocupam de descrever e analisar os processos concretos de transmissão do conhecimento e de produção do fracasso escolar, às desigualdades escolares ou culturais (LAHIRE, 2007). Ainda que relativamente poucas em número, essas pesquisas existem. Pensamos, em particular, naquelas desenvolvidas em torno de Élisabeth Bautier, Bernard Charlot e Jean-Yves Rochex (e aquelas conduzidas desde 1987 no âmbito da equipe ESCOL da Universidade Paris 8). Para esses autores, ligada às questões do capital cultural e das competências cognitivas, está a questão da relação com o saber, do significado que o aluno lhe confere, o que seria decisivo para entender os investimentos diferenciados na própria escolaridade e na aprendizagem, e para explicar as desigualdades que daí resultam (ver, por exemplo, CHARLOT; BAUTIER; ROCHEX, 1992; BAUTIER, CHARLOT; ROCHEX, 2000).

Esses avanços nos parecem tanto mais necessários quanto mais desponta uma nova cultura, esta "cultura digital" que frequentemente é oposta à cultura escolar, e invocada para explicar os problemas de motivação dos alunos e uma certa desorientação dos 
professores, os quais constatam que as disposições desenvolvidas atualmente por boa parte dos alunos não estão alinhadas às expectativas da escola (fala-se aqui de uma tendência de "zapping" que se traduziria por uma dispersão da atenção e incapacidade de manter a concentração; por uma escrita "SMS" que induziria a um relaxamento da ortografia..., todas essas ideias pré-concebidas que tendem a relativizar, ou mesmo invalidar, as pesquisas existentes). Por meio de atividades on-line, os indivíduos têm experiências diversas, algumas potencialmente formadoras; por isso é razoável supor que essas atividades representam espaços possíveis para a aprendizagem informal (BERRY, 2012) e não apenas obstáculos ou derivativos à aprendizagem. Em suma, o importante não é apenas o suporte do conhecimento em si, mas também o modo como ele é usado.

\section{Uma transmissão cultural não só "osmótica"}

Ao lado de trabalhos que buscam compreender por onde passam os efeitos do capital cultural sobre o desempenho escolar, outra forma de abrir a caixa preta do capital cultural é problematizar a questão de sua transmissão, interrogando como ela se dá concretamente. Esse questionamento parte do fato de que não há automatismos em matéria de herança cultural. 0 interesse na questão da transmissibilidade do capital cultural é contemporâneo de uma evolução importante observada na reflexão em torno da definição de capital cultural, a qual remete ao próprio estatuto do conceito: atualmente, estamos passando de uma visão de capital cultural como um atributo inexorável das classes superiores a uma visão de capital cultural como fruto de um processo a ser analisado (ROKSA; POTTER, 2011).

Não herdamos capital cultural como herdamos um patrimônio material ou capital econômico. Bourdieu já insistia nesse aspecto: o capital cultural "não pode ser transmitido instantaneamente (ao contrário do dinheiro, do certificado de propriedade ou mesmo do título de nobreza) por doação ou transmissão hereditária, compra ou troca" (BOURDIEU, 1979b, p. 4). Precisemos que estamos falando aqui de capital cultural em sua forma incorporada. 0 capital cultural objetivado é diretamente transmissivel: os bens culturais podem, de fato, ser objeto de uma apropriação material por meio do capital econômico, mas, em contrapartida, sua apropriação simbólica requer incorporação. 0 capital cultural incorporado é um "ter que se tornou ser, uma propriedade tornada corpo, tornando-se parte integrante da 'pessoa', um habitus. Aquele que o possui 'pagou com sua própria pessoa' e com o que tem de mais pessoal, seu tempo” (BOURDIEU, 1979b, p. 4).

A pesquisa atual, entretanto, se afasta da concepção de Bourdieu sobre transmissão cultural familiar, cujo caráter abusivamente mecânico tem sido fortemente contestado por Bernard Lahire (1995) e mais recentemente por Gaëlle Henri-Panabière (2010). Bourdieu sugere que a transmissão cultural ocorre essencialmente de uma maneira osmótica através do que ele chama de "efeito Arrow generalizado", a saber, "o fato de que toda propriedade cultural, pinturas, monumentos, máquinas e, especialmente, todos aqueles que fazem parte do ambiente natal, têm um efeito educacional por sua mera existência” (BOURDIEU, $1979 b$, p. 4). Certamente, é mais provável que uma criança se torne leitora se ela vê seus pais diariamente lendo e vive rodeada de livros à sua livre disposição, já que é verdade que a socialização passa em parte por imitação e impregnação. No entanto, a 
transmissão cultural familiar não ocorre apenas de maneira prática e inconsciente. Ao contrário da ideia de uma ação educativa exercida automaticamente pelo meio ambiente, pesquisas atuais indicam que não basta possuir uma biblioteca formidável para estimular o desenvolvimento intelectual da criança; é necessário transmitir-lhe o gosto pela leitura, o que implica um investimento parental significativo que requer tempo e que passa, por exemplo, pelo fato de ler precocemente histórias para o filho, por guiá-lo e acompanhálo em suas leituras... No que diz respeito à transmissão cultural, parece importante distinguir entre transmissão cultural familiar passiva ou "osmótica” e transmissão cultural familiar ativa ou "parentocrática" (BROWN, 1990), em que os meios e os desejos dos pais desempenham um papel central, cuja importância pode ser crescente para os pais que desejam transmitir seu capital cultural. De fato, não apenas a aquisição de capital cultural exige um trabalho de apropriação que não é óbvio, mas, além disso, essas pesquisas recentes mostram que o capital cultural é transmitido de forma modificada: as gerações mais jovens, sujeitas a influências culturais diversificadas, selecionam o que apropriam à luz do que lhes parece ainda ser útil e atual (HENRI-PANABIÈRE, 2010).

Em outras palavras, a transmissão cultural "vertical" (isto é, de pais para filhos) não é óbvia nem garantida e é compreensivel, nessas circunstâncias, que algumas crianças, na prática, não se beneficiem do capital cultural detido por seus pais. Se algumas pessoas falam hoje de uma "crise de transmissões culturais verticais" (PASQUIER, 2005) é, ao mesmo tempo, por razões relacionadas à evolução das famílias e estilos educacionais familiares (em geral, menos autoritários e mais democráticos do que antes, apesar das persistentes diferenças entre os grupos sociais; LE PAPE; VAN ZANTEN, 2009), mas também porque as crianças experimentam universos culturais plurais que não são de forma alguma redutíveis à cultura familiar (LAHIRE, 1998). A educação familiar se vê em concorrência com outras instâncias de socialização, a mídia e o grupo de pares, em particular. A pressão dos colegas sobre o adolescente (e, através deles, a indústria cultural) é particularmente importante. 0 grupo exerce uma poderosa pressão sobre seus membros, o que reduz suas possibilidades de afirmar sua identidade, especialmente a cultural; é a "tirania da maioria" da qual fala Pasquier (2005) e que contribui para uma relativa homogeneização da cultura adolescente ${ }^{20}$. 0 controle parental da transmissão cultural é, portanto, cada vez mais difícil.

Salientemos aqui a contribuição em termos metodológicos de uma sociologia qualitativa, combinando entrevistas biográficas e observações finas, permitindo assim levar em conta as variações entre indivíduos no interior de um mesmo grupo ou classe social, no contexto de uma sociologia das irregularidades sociais e dos casos improváveis, de uma sociologia que busca captar o social em sua forma singularizada, individualizada (LAHIRE, 1998, 2013). 0 questionamento sobre a transmissibilidade do capital cultural supõe ainda uma acepção relativamente ampla do conceito, que se estende aos modos de uso dos bens e práticas culturais focalizados e às disposições a eles relacionadas e que são transferiveis para outros bens e práticas (LAHIRE, 2004).

20- Embora possamos falar de um universo cultural comum aos adolescentes, os sociólogos que os observam atentamente constatam que a cultura juvenil é expressa de várias maneiras (notadamente com fortes diferenças entre meninos e meninas e diferenças significativas também por idade, com cada idade definindo universos culturais muito específicos; OCTOBRE et al., 2010). 
Em resumo, com base no que acaba de ser apresentado em relação às pesquisas que visam a abrir a caixa preta do conceito de capital cultural, duas coisas se destacam:

\begin{abstract}
- se a cultura importa para o sucesso escolar, não é unicamente por uma razão arbitrária (conforme a ideia de que a escola valorizaria certos conteúdos culturais mais ou menos alinhados com a cultura das diferentes classes sociais), mas, porque ela produz efeitos e disposições cognitivas. Esta é uma contribuição decisiva das pesquisas que objetivam detectar as práticas escolarmente eficazes dentre aquelas recobertas pela defınição restrita de capital cultural;

- de forma complementar, as pesquisas que estudam as condições práticas da transmissão cultural e, em particular, da socialização na leitura, tendem a indicar que esses efeitos e disposições cognitivas favoráveis ao sucesso escolar são difíceis de produzir e de controlar. Sua eficácia, portanto, não é garantida.
\end{abstract}

$\mathrm{Na}$ medida em que as famílias são incapazes de controlar a socialização de seus filhos do começo ao fim e porque a lucratividade da transmissão cultural torna-se incerta, observa-se uma evolução na forma como os pais das classes média e alta tentam reproduzir seu status social. Além do desenvolvimento de uma relação cada vez mais reflexiva e estratégica com as práticas de socialização cultural, cognitiva e linguística, novas estratégias estão sendo desenvolvidas, nas quais o capital cultural não está ausente, mas vê seu lugar e seu papel modificado.

\title{
A crítica indireta: interdependência e convertibilidade de capitais
}

0 que acaba de ser dito leva-nos a considerar uma terceira contribuição para a questão de saber se o conceito de capital cultural ainda é pertinente para a compreensão da reprodução social pela escola: a contribuição da pesquisa sobre a formação das elites e as estratégias educativas das famílias das classes médias e superiores. Esta literatura tende a mostrar que há toda uma série de comportamentos e estratégias que facilitam o sucesso escolar e o acesso a contextos educacionais favoráveis, mas, que dificilmente são tematizados ou incluídos no conceito de capital cultural, em particular sob sua forma restrita. É o caso de práticas educativas como a escolha do estabelecimento e do tipo de ensino para os filhos (VAN ZANTEN, 2009a), a busca de informações sobre as orientações e o funcionamento pedagógico interno das escolas (HÉRAN, 1996; DRAELANTS, 2014), a internacionalização dos percursos escolares (WAGNER, 2007; BALLATORE, 2010), o recurso às aulas particulares (GLASMAN, 2001) e até mesmo ao coaching (OLLER, 2012). Embora nos ensinem muito sobre o papel e o lugar da cultura na reprodução social, essas pesquisas, diferentemente daquelas apresentadas até agora, não discutem diretamente o conceito de capital cultural. É nesse sentido que falaremos de crítica indireta. É igualmente necessário dizer que as práticas familiares mencionadas em apoio a esta tese referem-se principalmente ao ensino secundário ou superior e, portanto, ocorrem bem após a socialização primária.

Em nossa opinião, a contribuição dessas pesquisas é mostrar que as práticas parentais mais rentáveis no mundo escolar, nestes níveis de ensino, não necessitam obrigatoriamente de transmissão cultural de pais para filhos. É muito mais o conhecimento das engrenagens e a familiaridade com o funcionamento do sistema escolar que serão decisivos na criação 
de estratégias reais de reprodução social (DRAELANTS, 2014). Isso não significa que a questão do capital cultural não se coloque mais nesse contexto. Pelo contrário, a aquisição de capital cultural continua sendo o objetivo dessas novas estratégias. Mesmo porque se trata, em última análise, para essas famílias, de garantir que seus filhos recebam um certificado escolar, de preferência não desvalorizado. Ao sugerir que essas estratégias não exigem necessariamente a transmissão cultural de pais para filhos, queremos enfatizar duas coisas diferentes: de um lado, que essas estratégias não exigem a transmissão cultural direta de pais a filhos; de outro, que elas não visam necessariamente à aquisição de capital cultural incorporado. Nós detalharemos abaixo esses dois aspectos. Essas novas estratégias também apelam para o capital social e econômico dos pais, não apenas para o seu capital cultural. Isso leva ao problema da interação e interdependência entre o capital cultural e as outras formas de capitais e à questão da convertibilidade entre elas.

\section{De uma transmissão cultural direta a uma transmissão cultural indireta}

Além da distinção já feita neste artigo entre transmissão cultural passiva e ativa, é heurístico distinguir entre transmissão parental direta e indireta de capital cultural. A transmissão cultural indireta implica, em certos casos, o uso de intermediários que são pagos e que permitem transmitir capital cultural de maneira oblíqua ou "por procuração", como diria Bourdieu (1979b). Conscientes da dificuldade de controlar de maneira efetiva a socialização de seus filhos, alguns pais realmente privilegiam o recurso a intermediários profissionais (aulas particulares e coaching) e/ou tentam limitar as influências culturais potencialmente prejudiciais, limitando, tanto quanto possível, o ambiente social de seus filhos a um "entre nós", percebido como protetor. Se a escolha do estabelecimento de ensino é percebida como uma questão tão importante é porque garante um mínimo de controle sobre os colegas com quem eles irão conviver (FELOUZIS; PERROTON, 2010; VAN ZANTEN, 2009b). A transmissão que é realizada na escola em matéria cultural não é apenas uma questão de inculcação escolar. Ela depende também, se não acima de tudo, de uma socialização informal que reflete inevitavelmente as características sociais e culturais do público escolar, ou seja, de um efeito dos pares. Em um tempo no qual os herdeiros constituíam a maioria das matrículas escolares, esta educação informal pelos pares poderia ser ignorada. Hoje isso é mais difícil, já que o desajuste cultural entre a escola e os adolescentes está aumentando. 0 fato de que o lazer das crianças se afasta do de seus pais durante o período da adolescência não se traduz, portanto, mecanicamente, em declínio da influência dos pais. 0 controle da companhia, e de com quem os filhos se relacionam, permite que eles continuem indiretamente orientando os gostos e hábitos culturais dos filhos, o que também explica porque a herança cultural raramente se dá de modo completo, dando origem a discrepâncias ou deslizes mais ou menos assumidos e antecipados pelos pais (RENARD, 2013).

Se essas estratégias de reprodução não necessitam forçosamente de uma transmissão cultural ou, em todo caso, de uma transmissão vertical direta de pais para filhos, elas implicam por parte dos pais uma vigilância e um acompanhamento próximo da escolaridade 
deles envolvendo um grande investimento, em particular, das mães (VINCENT, 2010). Devese notar também que essas estratégias de reprodução estão longe de serem homogêneas segundo as diferentes frações das classes médias e superiores. 0 investimento em aulas particulares, serviços de coaching, estudo de idiomas e períodos de estudo no exterior é privilegiado pelas classes médias superiores, especialmente aquelas com maior capital econômico (engenheiros, profissionais liberais, empresários, executivos corporativos, gerentes...), que também são as que têm maior probabilidade de controlar estritamente o ambiente de seus filhos (através de toda uma série de escolhas, desde a instituição de ensino e as atividades extraescolares, até os passeios ou a escolha dos colegas de sala a serem convidados à casa (GOMBERT; VAN ZANTEN, 2004; VAN ZANTEN, 2009B; BALLATORE, 2010). As famílias populares e as de classes médias baixas têm maior probabilidade de recorrer à transmissão vertical. 0 trabalho de acompanhamento dos deveres escolares é, por exemplo, uma prática generalizada nesses contextos. A pesquisa de Kakpo (2009) sobre a supervisão dos deveres em meio populares mostra que os efeitos do envolvimento ativo dos pais no acompanhamento escolar não são socialmente homogêneos. Eles parecem ser, de fato, proporcionais à importância do capital cultural incorporado dos pais. Quando os recursos culturais são escassos ou inadequados, o envolvimento direto na transmissão cultural corre o risco de ser contraprodutivo, daí o interesse em usar seu capital social ou econômico para recorrer a intermediários competentes ao invés de se envolver diretamente ${ }^{21}$.

\section{De competências cognitivas a competências comportamentais}

As estratégias de reprodução escolar que decorrem de uma transmissão ativa ou parentocrática (por oposição a uma transmissão osmótica) podem ser diretas ou indiretas, como acabamos de ver. Estratégias indiretas, embora exijam forte atenção dos pais e controle rígido do ambiente, parecem mais fáceis de implementar do que estratégias diretas. Chamar os profissionais (professores particulares, coaches, etc.) ou controlar as amizades e companhias dos filhos (através da escolha das atividades extraescolares e da própria instituição de ensino) requer, acima de tudo, capital econômico e social. No entanto, tentar transmitir o amor pela leitura (a principal atividade cultural cuja lucratividade acadêmica permanece inquestionável) requer tempo.

No entanto, o tempo disponível para articular ou conciliar vida privada e vida profissional (e, portanto, cuidar das crianças, no caso de uma família) tende geralmente a faltar, devido ao acelerado ritmo de vida (ROSA, 2013), embora varie de acordo com a ocupação e o sexo dos trabalhadores (PAILHÉ; SOLAZ, 2009). Para gerentes e membros de profissões intelectuais superiores, em que os horários de trabalho costumam exceder 40 horas por semana, a hiperatividade profissional pode ser compensada pelo trabalho em tempo parcial ou pela inatividade voluntária de um dos membros do casal, a mulher, tipicamente, que, neste caso, coloca sua carreira entre parênteses para se dedicar à educação das crianças. A norma é, no entanto, de casais com dupla atividade, para quem

21- Deve-se notar que os mais necessitados de tais intermediários são também aqueles que têm menos possibilidade financeira para isso. 
o tempo representa claramente mercadoria rara. Essa falta de tempo ajuda a explicar que eles deleguem, quando possuem os meios, parte da atividade educacional a terceiros, como vimos. A baixa disponibilidade e o cansaço ocasionado pelo excesso de trabalho também enfraquecem as disposições ascéticas características da norma tradicional da legitimidade cultural e desviam os pais das classes médias altas de atividades culturais domésticas com objetivos cognitivos, como a leitura, que eles tendem a substituir por atividades culturais públicas com objetivos comportamentais e distintivos, como ir a exposições, vernissages (COULANGEON, 2011).

Não é, portanto, surpreendente constatar que um certo número de novas estratégias de reprodução social implementadas pelas classes médias altas não visem tanto a produzir efeitos cognitivos sobre as crianças, quanto desenvolver nelas competências comportamentais (FARKAS, 2003). As competências comportamentais em questão remetem aos "soft skills" ou competências interpessoais e comunicacionais requeridas, em particular, pelos recrutadores no mercado de trabalho de executivos, onde o importante para se destacar da multidão é menos demonstrar um capital cultural incorporado ao fim de uma longa socialização, do que ser capaz de apresentar sua personalidade sob uma luz favorável, considerando critérios comportamentais valorizados e avaliados neste contexto (envolvimento, dinamismo, adaptabilidade, etc. (BROWN; HESKETH, 2004).

Isso não significa que o capital cultural incorporado esteja fora de jogo, o qual, evidentemente, não é independente das competências comportamentais e pode ser considerado como condicionante delas, na medida em que a desenvoltura social está incluída na definição ampla do conceito de capital cultural. Embora o capital cultural cognitivo desempenhe um papel cada vez menos central no processo de seleção escolar, o esforço para se cultivar ainda é necessário para obter um diploma. 0 objetivo principal das novas estratégias de reprodução escolar é obter o capital cultural em sua forma institucionalizada, dadas as propriedades originais e únicas que o caracterizam. 0 capital cultural institucionalizado é, de fato, o único tipo de capital cultural que, por meio da “magia performativa do poder de instituir" (BOURDIEU, 1979b, p. 5), contém o poder de fazer reconhecer a seu detentor um certificado de competência cultural que não precisa mais ser demonstrado. Dito isto, o capital cultural institucionalizado, embora mais do que nunca necessário para se integrar social e profissionalmente, é cada vez menos suficiente para a distinção social. A esse respeito, o trabalho de Brown e Hesketh (2004), sobre os procedimentos de recrutamento para cargos altamente qualificados e remunerados, mostra que o desenvolvimento de técnicas para avaliar a própria personalidade do candidato está diretamente relacionado à inflação de diplomas, na medida em que estes últimos informam menos os recrutadores sobre os candidatos e não lhes são mais suficientes para triá-los.

Os diplomas, pelo menos aqueles que têm valor, não podendo (ainda) serem comprados, pode-se considerar que os capitais sociais e econômicos ainda não são totalmente autônomos em relação ao capital cultural. Dito isso, entre as novas competências comportamentais, algumas exigem acima de tudo capital econômico e eventualmente capital social. 0 exemplo de mobilidade geográfica desenvolvido abaixo ilustra bem isso. Num mundo globalizado, o desenvolvimento de disposições à mobilidade e ao multilinguismo é visto como uma habilidade particularmente útil. "0 aumento do poder desses novos atributos culturais de dominação anda de mãos dadas 
com um domínio, simbólico e material, do espaço, ao passo que as antigas formas de capital cultural solicitavam bem mais fortemente o domínio do tempo" (COULANGEON, 2011, p. 149). Mas, obter competências migratórias, capital espacial e internacional, como novas formas de capital cultural, de acordo com a definição ampla do conceito, não pode ser feito sem capital econômico. Isso nos leva a observar que o tipo de capital cultural que está ganhando cada vez mais peso hoje é cada vez menos independente do capital econômico, como mostra o exemplo que vamos desenvolver, relacionado à capacidade de se mobilizar para obter acesso às melhores instituições de ensino e às ofertas educacionais mais promissoras, e de desenvolver competências de mobilidade e de comunicação que permitem passar de um idioma a outro, de um universo cultural a outro. Todos esses "soft skills" se tornaram indispensáveis para que se possa aspirar a determinadas posições sociais que estão se internacionalizando, ainda que, de acordo com os contextos nacionais, o capital cultural desempenhe um papel diferente na reprodução de posições sociais e na evolução das carreiras ${ }^{22}$.

\section{Exemplo da mobilidade geográfica e capital cultural de tipo internacional}

A análise espacial das desigualdades é bastante antiga na sociologia urbana e bem mais tardia na sociologia da educação. No entanto, já no livro Os herdeiros, Bourdieu e Passeron sublinham que "o fator geográfico e o fator da desigualdade cultural nunca são independentes, pois, as chances de residir em uma cidade grande, onde as possibilidades de acesso à educação e à cultura são maiores, crescem à medida que se sobe na hierarquia social" (p. 40). Eles falavam então de "diferenças importantes que são devidas à natureza da relação que os parisienses têm com a instituição universitária” (p. 73). 0 trabalho de Oberti (2007) confirma esta oposição Paris-província e mostra claramente que os municípios mais favorecidos têm maior número de colégios com diferentes opções de percurso (inclusive com percursos internacionais), com ensino de línguas raras, com classes em horários especiais, com professores mais qualificados e mais experientes. Em outras palavras, é menos o fato de ser um detentor de capital cultural que está em jogo aqui, e mais o fato de se viver no centro da cidade, neste caso em Paris, o que requer, acima de tudo, capital econômico, dado o alto preço do metro quadrado dos imóveis na cidade.

Essa concentração da oferta escolar dita de "excelência" nos centros das cidades é atualmente uma fonte de desigualdades flagrantes. Na França, os filhos das famílias populares são os que menos têm mobilidade e os que mais obedecem aos ditames da política pública que determina a matrícula em escolas do mesmo setor de moradia (HÉRAN, 1996; VAN ZANTEN, 2001), enquanto as "elites", qualquer que seja o país, tendem a separar local de moradia e espaço escolar. Estas últimas operam em uma lógica da "performance", da busca de excelência, que escapa frequentemente às categorias socioprofissionais mais modestas (SANSELME, 2009). Para além dos discursos sobre a inclusão, como lembra

\footnotetext{
22- Lamont, por exemplo, mostrou que a relação de familiaridade que os indivíduos mantêm nos Estados Unidos com a cultura legítima desempenha um papel menos importante no sucesso social do que na França. Ao procurar se diferenciar ou classificar os outros em grupos de status, os membros da classe média alta americana estão, de fato, mais atentos às características morais (centradas em qualidades como a honestidade) e socioeconômicas (a posição dos indivíduos segundo sua renda, poder e sucesso profissional) do que ao capital cultural (LAMONT, 1995).
} 
Oberti (2007), a realidade da recusa da mistura social no interior dos estabelecimentos de ensino, bem como em certos bairros das cidades, é patente. Aliás, a noção de segregação remete a uma intencionalidade, a um desejo de distanciamento de certos grupos sociais e de busca de um "entre si" 23 , que a escolha do estabelecimento de ensino ou a flexibilização das políticas de matrícula setorizada permitem hoje (VAN ZANTEN, 2009a).

No atual contexto de internacionalização do ensino superior, a europeização das políticas educativas, nomeadamente através dos objetivos fixados em Lisboa, em março de 2000, que sublinham a necessidade de formar uma mão-de-obra "qualificada e flexível em mercados de trabalho europeus mais abertos e acessiveis" e para tornar a Europa uma "economia do conhecimento" competitiva, parece que as segregações socioespaciais se tornam mais pronunciadas. As hierarquias nacionais já existentes nos sistemas de ensino superior e no espaço europeu de educação e formação ao longo da vida, visando a contribuir para a mobilidade dos cidadãos, tornaram essa última de uma importância crucial para a constituição de uma bagagem cultural distintiva (BALLATORE, 2010).

Wagner fala da cultura internacional como de uma instância que liga o nacional, o local e o internacional e modela uma relação particular com as "identidades" (WAGNER, 1998), valorizada e valorizável neste contexto. 0 distanciamento da origem, que permite que nos adaptemos e possamos nos inserir nos círculos internacionais, é cada vez mais vista como um sinal distintivo em nossas sociedades mutantes, mesmo que as elites não tenham abandonado suas credenciais nacionais ${ }^{24}$. É antes o domínio do "jogo com seus atributos nacionais", para usar os termos de Wagner, constituídos de recursos educacionais, linguísticos, profissionais ou sociais, que poderiam modificar a composição do capital cultural das elites da globalização. De fato, "os executivos que se definem firmemente como internacionais também são os mais ligados à sua nacionalidade. 0 paradoxo é apenas aparente. As famílias mais internacionais são também aquelas que mobilizam mais sistematicamente seus recursos nacionais, nas estratégias reprodutivas, na vida profissional e em todas as dimensões da vida social. Essa relação estratégica com o nacional é constitutiva da cultura internacional” (WAGNER, 1998, p. 190).

Além disso, a fim de analisar a diversidade dos usos nacionais do internacional, é importante levar em conta a capacidade dos Estados e das estruturas nacionais de produzir sua própria definição de "excelência", uma capacidade que depende, em parte, do poder econômico e político do país. São questões nacionais que dão sentido ao investimento internacional. Em outras palavras, o internacional não é definido em si, mas, em relação, por oposição a uma relação exclusiva com o nacional. Assim, as estratégias internacionais mais bem sucedidas são aquelas que Wagner qualifica como "diplomáticas", pois, se as qualidades "diplomáticas" são qualidades internacionais, o prestígio do diplomata vem do fato de que ele representa um país.

Do lado dos indivíduos, a mobilidade internacional, fortemente encorajada hoje, gera estratégias de aprendizagem cada vez mais precoces e variadas de aquisição linguística e cognitiva, imposta pelas relações de poder em evolução em uma sociedade cada vez mais

23 - No sentido de estar entre iguais (NT).

24 - Nesse sentido, essa cultura é mais "internacional" do que "cosmopolita" porque não nega a nação. É o acúmulo de capitais que é valorizado e não a negação dos capitais adquiridos em um dado nível, em uma dada escala nacional ou local. 
internacional. 0 desenvolvimento de programas comunitários de mobilidade não pode ser lido independentemente da nova composição social dos fluxos migratórios e de certa "globalização" da economia. As multinacionais estão, de fato, na origem do advento de uma "classe capitalista transnacional" (SKLAIR, 2001). Líderes de grandes corporações e políticos, assistidos por burocratas, profissionais internacionalizados e alguns meios de comunicação, trabalham agora juntos para impor a ideia da necessidade de competição global e de uma ideologia consumista para o bem-estar de todos. Assim, a tendência de privatizar e colocar em competição esferas inteiras da economia, antes protegidas dos caprichos do mercado, está se acelerando, como a tendência de compartilhar um estilo de vida transnacional particular, em bairros residenciais cada vez mais protegidos, longe de uma população mais sedentária.

Vários estudos na sociologia urbana, na antropologia, mas, também, na sociologia da educação e da migração, fizeram emergir nos últimos anos a ideia de que a "mobilidade" também era um "capital" (MURPHY-LEJEUNE, 2002, 2007; BALLATORE, 2010); o que implica conceber a mobilidade não como um deslocamento em si, mas como uma "capacidade de", um potencial de deslocamento. Esse uso, como potencial de deslocamento, é difundido nos trabalhos de sociólogos, mas também de geógrafos (LÉVY, 1999) e urbanistas (ORFEUIL, 2004). A mobilidade pode assim tornar-se um fator de diferenciação e desigualdade, porque constitui uma condição de participação na vida social (notadamente em termos do acesso à formação, ao emprego, etc.) e seria, portanto, também um fator de coesão e inclusão. Ao adotar uma definição ampla de capital cultural, é possível vislumbrar a mobilidade como uma forma reconstituída de capital cultural que poderia ser descrita como um capital cultural internacional, evitando assim contribuir para a multiplicação de tipos de capital, tal como denunciado por Neveu (2013).

0 desenvolvimento de intercâmbios no ensino superior e a institucionalização da mobilidade, certamente, transformaram as condições de acesso a esse capital cultural internacional outrora reservado a uma pequena elite. Mas, os sistemas de educação internacionais ainda são objeto de uma democratização relativa das competências internacionais: por exemplo, o programa Erasmus só permite que menos de 5\% dos estudantes universitários europeus estudem no exterior, contrariamente à sua imagem de um programa de intercâmbio "popular". Embora filmes e reportagens tenham alimentado abundantemente mitos sobre a mobilidade estudantil, a norma ainda é a falta de mobilidade (BALLATORE, 2010). A oferta de intercâmbios no exterior varia também de uma disciplina a outra, e de acordo com as instituições. São os cursos mais seletivos dos sistemas nacionais de ensino secundário e superior os que apresentam as taxas mais elevadas de mobilidade estudantil na Europa. Os alunos dos setores mais nobres do ensino superior são cada vez mais numerosos a ir para o exterior, durante ou logo após seus estudos, e fazem investimentos de longo prazo. A abertura internacional defendida pelas políticas europeias também parece estar muito desigualmente desenvolvida no território europeu.

Além disso, às desigualdades no acesso à mobilidade se acrescentam as desigualdades no "sucesso" nos percursos migratórios, os quais variam muito dependendo das rotas adotadas. As diferentes mobilidades não têm a mesma rentabilidade. Ao contrário das ideias difundidas, hoje são mais valorizados os países de destino do que os movimentos 
para ter acesso aos cursos de prestígio e para se inserir profissionalmente e fazer carreira (BOUSSARD, 2013). 0 estudo comparativo da inserção profissional de egressos do Programa Erasmus, em diferentes países, mostra que é em relação a cada um dos contextos nacionais e locais que se deve distinguir situações nas quais o estudo no exterior representa uma etapa quase que obrigatória de sucesso social, daquelas em que ele não representa mais do que um refúgio em uma universidade de massa, ou ainda daquelas escolhas que podem comprometer a boa inserção nacional, se o afastamento se tornar permanente (BALLATORE, 2013a, 2013b).

A rentabilidade dos percursos migratórios é também função do "capital” migratório já possuído (BALLATORE, 2010; CARLSON, 2013), que depende do passado migratório dos indivíduos, dos meios de deslocamento, das competências linguísticas e de comunicação que envolvem um alto nível de desenvoltura social e um bom domínio de auto-apresentação em ambientes e idiomas variados. Competências que podem ser adquiridas durante intercâmbios linguísticos caros, mas que são mais facilmente ainda adquiridas em famílias internacionais, particularmente naquelas de profissionais que circulam no mundo globalizado e que frequentemente escolhem escolas multilíngues ou experimentais para seus filhos (WAGNER, 1998; HAYDEN, 2006). Para utilizar de forma rentável os dispositivos de mobilidade, é preciso conhecê-los, ser capaz de discutir com os profissionais que os operam, encontrar a pessoa certa, escolher o período certo e o destino certo. Aqui as competências linguísticas e comportamentais se associam aos conhecimentos culturais e com as relações sociais. Cada território tem, com efeito, seus próprios códigos e usos e se vê frequentemente colocado em um continuum em termos de desenvolvimento e prestígio. 0 acesso a esse novo tipo de capital cultural e sua rentabilidade pressupõem, portanto, a posse de formas mais clássicas de capital cultural, mas, também, de capitais econômicos e sociais.

Por fim, os usos do internacional variam de acordo com as diferentes frações das classes médias altas. Traçando vários tipos de trajetórias internacionais e analisando origens sociais, áreas de estudo, idade e setores de atividade, Wagner observa que, para as classes médias altas com forte capital cultural (filhos de jornalistas, professores), o internacional se inscreve em "estratégias de ascensão social e funciona como um multiplicador de capital cultural”. A representação importante, entre quadros internacionais, de filhos de militares, de altos funcionários públicos e de professores no exterior (frequentemente nas antigas colônias francesas) reflete outras formas de estratégia. "Os recursos internacionais acumulados em meios socioprofissionais ligados ao estado podem ser 'reconvertidos' em carreiras internacionais nas empresas." Os ramos de estudos internacionalizados constituem, na sequência, um "refúgio" que permite aos jovens de alta origem social, muitas vezes, da burguesia, compensar um relativo fracasso escolar. Para os estudantes Erasmus de cursos não seletivos, estudar noutra instituição estrangeira e permanecer noutro país durante alguns meses é também considerado como formador e valorizador. Essa valorização não é sentida, pelo estudante, apenas como uma gratificação em razão da personalização de sua trajetória, mas, significa também um retorno do investimento concreto e material (BALLATORE, 2010). No entanto, pode-se perguntar se é a permanência no exterior ou a morfologia social e acadêmica dessa população (que, em média, se destaca positivamente 
nesses dois aspectos em relação à massa dos estudantes) que torna a sua inserção no mercado de trabalho mais fácil.

0 exemplo da mobilidade geográfica, aqui brevemente desenvolvido, é, portanto, parte de uma tendência mais geral: aquela que progressivamente vê a excelência escolar sendo construída à sombra de atividades para-escolares onerosas, como aulas particulares e intercâmbios linguísticos. A transição de um modo de reprodução de posições sociais baseado na proximidade da cultura escolar, para um modo de reprodução determinado pela qualidade dos ambientes escolares frequentados e por um conhecimento das trajetórias escolares mais rentáveis poderia ser sinônimo de um forte retorno à conversibilidade do capital econômico e social em capital cultural. As novas formas de capital cultural tendem igualmente a ser mais dependentes do capital econômico e social, na medida em que estes últimos multiplicam seus efeitos e condicionam sua rentabilidade, como foi visto no caso das formas espaciais e internacionais de capital cultural.

\section{Conclusão}

0 objetivo deste artigo foi o de interrogar a pertinência atual do conceito de capital cultural para entender a reprodução social pela escola. A partir de uma revisão de literatura, mostramos que a resposta a essa questão varia de acordo com a própria definição de capital cultural adotada. Se adotarmos a definição restrita do conceito, que associa o capital cultural à cultura erudita, tenderemos a responder negativamente em razão do declínio social generalizado da alta cultura. Somente as práticas de leitura permaneceriam eficazes para o sucesso escolar. Nesse sentido, se a cultura desempenha um papel na reprodução social pela escola, não é apenas por razões de um arbitrário cultural, mas porque a leitura ajuda a desenvolver competências cognitivas e linguísticas úteis para a aprendizagem em geral. Mas, se optarmos pela definição ampla do conceito que remete a uma diversidade de práticas e normas educacionais, cujo conteúdo não é fixo, mas que permanece apanágio das classes dominantes, tender-se-á, pelo contrário, a considerar que o capital cultural permanece pertinente para se compreender a reprodução social. Ao invés de tentar separar essas duas abordagens, optamos por enfatizar suas complementaridades. A primeira abordagem tem a vantagem de destacar a relativa novidade do processo cultural em curso; o interesse da segunda é lembrar que, para além das mudanças no conteúdo do capital cultural, o efeito permanece inalterado. Podem não ser os mesmos recursos (aqueles da "cultura erudita") que importam, mas, independentemente de seu conteúdo em evolução, alguns recursos ainda fornecem acesso a recompensas raras. Os novos recursos são, portanto, o equivalente funcional dos antigos.

Dito isso, além da rentabilidade do capital cultural, alguns autores levantam outra questão essencial, a da sua transmissibilidade, que foi vista por muito tempo como automática. A transmissão de hábitos culturais educacionalmente rentáveis, como as práticas de leitura, requer, na realidade, um investimento parental complexo, demorado e de eficiência incerta. É por isso que os pais da classe média alta também estão desenvolvendo estratégias indiretas de transmissão cultural que os levam a convocar profissionais (professores particulares, coaches) e a prestar muita atenção no processo de escolha do 
estabelecimento de ensino que, quando conduzido por uma preocupação de estar entre si, garante um mínimo de controle cultural. Entre as novas estratégias de reprodução escolar privilegiadas pelas classes médias altas, também observamos o crescente papel das estratégias voltadas para a aquisição de competências comportamentais mais do que cognitivas. 0 exemplo da mobilidade geográfica ilustra essa mudança, ao possibilitar o desenvolvimento de competências de comunicação, como a proficiência em língua estrangeira e, em geral, o acesso ao capital cultural de tipo internacional. Enfatizamos, em relação a essas estratégias indiretas e comportamentais, a importância da posse de capital econômico e social, levantando assim a questão da interdependência e conversibilidade entre os diferentes tipos de capital.

Em suma, se aceitarmos a ideia de que o capital cultural é um conceito em movimento cuja composição é suscetível de evoluir, torna-se imperioso constatar que o capital cultural está longe de estar obsoleto. Nesse sentido, poder-se-ia considerar, em alguma medida, que os diferentes tipos de pesquisa convergem na observação de que "tudo tem que mudar para que nada mude”, para usar a famosa frase do personagem central do romance $O$ guepardo, de Giuseppe Tomasi di Lampedusa. Contudo, é importante sublinhar aqui uma diferença fundamental entre as formas clássicas e as novas formas do capital cultural: essas últimas, que incluem, em particular ${ }^{25}$, uma dimensão espacial ou mesmo internacional, não constituem uma forma autônoma de capital cultural, mas, decorrem dessas espécies mais que nunca dominantes de capital que são o capital econômico e o capital social. As frações das classes médias superiores mais bem dotadas de capital social e econômico são, portanto, os beneficiários diretos dessa evolução.

Embora muitos resultados das pesquisas sobre estratégias e práticas educativas parentais nas classes média e alta deem crédito a essa leitura, mais pesquisas são necessárias para confırmá-la e refiná-la. Analisar especificamente como se articulam as diferentes formas de transmissão cultural (das mais clássicas e "osmóticas" às mais recentes e "parentocráticas", diretas ou indiretas) e como, no seio das classes médias e altas, essas formas se distribuem e com quais resultados, nos parece igualmente configurar pesquisas que mereceriam ser realizadas. Aliás, dentre as novas estratégias de reprodução escolar, algumas dependem principalmente do capital social e do capital econômico, e levam a resultados comportamentais. Mas, estes últimos são realmente rentáveis? Como eles se articulam com os resultados (outcome) cognitivos? Os dois evoluem juntos...? Certamente este artigo deixa em aberto questões importantes que somente pesquisas empíricas futuras podem responder.

Assinalemos, por fim, que a literatura aqui revisada nos levou, efetivamente, a abordar a questão da ligação entre capital cultural e reprodução escolar e social, de modo distante da questão da socialização familiar e escolar primária. 0 que ficou expresso no fato de termos privilegiado uma abordagem pelo topo do sistema educativo, optando por focalizar, na última parte do texto, a questão da mobilidade internacional. Portanto, a área de pertinência de nossa análise diz respeito essencialmente ao ensino superior e

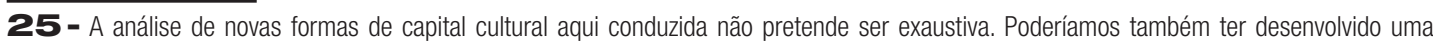
dimensão informacional relacionada à questão da orientação escolar e da escolha do estabelecimento de ensino. Alguns sociólogos que defendem a definição ampla do conceito de capital cultural consideram que o conhecimento dos arcanos do sistema escolar é parte do capital cultural. Essa é uma ideia presente, particularmente, em McDonough (1997) e van Zanten (2009a), que falam de "capital cultural de tipo informacional". Abordamos esse assunto em um artigo anterior (ver DRAELANTS, 2014). 
ao ensino médio, quando se perfila a perspectiva da direção a ser tomada e da própria escolha do curso superior. Ao fazer isso, enfatizamos fortemente as novas formas de capital cultural, como o capital cultural internacional, e relativizamos a importância de suas formas mais clássicas. No entanto, se a socialização cultural, cognitiva e linguística já não é mais suficiente, por si só, para explicar a reprodução social, ela continua, aos nossos olhos, a ser determinante quando nos aproximamos da socialização primária, e quando se trata de explicar os fenômenos de segregação ou fracasso escolar precoces, os quais, frequentemente, se associam à falta de um domínio mínimo da linguagem.

\section{Referências}

BALLATORE, M. Erasmus et la mobilité des jeunes européens. Paris: PUF, 2010.

BALLATORE, M. Revenir et repartir! Trajectoires d'étudiants Erasmus du sud et du nord de l'Europe. Cahiers Québécois de Démographie, v. 42, n. 2, p. 335-369, 2013 a.

BALLATORE, M. Partir en Erasmus: et après? Parcours comparés d'insertion profession- nelle. Spirale: Revue de Recherches en Éducation, n. 51, p. 59-81, 2013b.

BAUTIER, É.; CHARLOT, B.; ROCHEX, J.-Y. Entre apprentissages et métier d'élève: le rap- port au savoir. In: VAN ZANTEN, A. L'école, l'état des savoirs. Paris: La Découverte, 2000. p. 179-188.

BERGER, I. Les instituteurs d'une génération à l'autre. Paris: PUF, 1979.

BERNSTEIN, B. Langage et classes sociales: codes socio-linguistiques et contrôle social. Paris: Minuit, 1975.

BERRY, V. L'expérience virtuelle: jouer, vivre, apprendre dans un jeu vidéo. Rennes: Presses Universitaires de Rennes, 2012.

BOUSSARD, V. Injonction de mobilité et différenciations de carrière pour les cadres: le cas de la mobilité géographique. Rapport de Recherche IRES, 2013. En ligne: http://ses-info.fr/IMG/ pdf/Mobilite_geographique_et_ascension_ sociale_2_.pdf. Consulté le: 6 sept. 2014.

BOURDIEU, P. La distinction: critique sociale du jugement. Paris: Minuit, 1979a.

BOURDIEU, P. Les trois états du capital culturel. Actes de la Recherche en Sciences Sociales, v. 30, p. 3-6, 1979b.

BOURDIEU, P.; PASSERON, J.-C. La reproduction: éléments pour une théorie du système d'enseignement. Paris: Minuit, 1970.

BOURDIEU, P.; PASSERON, J.-C. Les héritiers: les étudiants et la culture. Paris: Minuit, 1964.

BROWN, P. The "Third Wave": education and the ideology of parentocracy. British Journal of Sociology of Education, v. 11, n. 1, p. 65-85, 1990.

BROWN, P.; HESKETH, A. The mismanagement of talent: employability and jobs in the knowledge economy. Oxford: Oxford University Press, 2004.

CARLSON, S. Becoming a mobile student: a processual perspective on German degree student mobility. Population, Space and Place, v. 19, p. 168-180, 2013.

CHARLES, F.; CIBOIS, P. L'évolution de l'origine sociale des enseignants du primaire sur la longue durée: retour sur une question controversée. Sociétés Contemporaines, n. 77, p. 31-56, 2010. 
Hugues DRAELANTS; Magali BALLATORE

CHARLOT, B.; BAUTIER, É.; ROCHEX, J.-Y. École et savoirs dans les banlieues... et ailleurs. Paris: Armand Colin, 1992. COULANGEON, P. Les métamorphoses de la distinction. Paris: Grasset, 2011.

DAGIRAL, E.; TESSIER, L. La délicate articulation des cultures scolaire et jeune: les usages de twilight de quelques professeurs d'un lycée de ZEP. In: COLLOQUE ENFANCE ET CULTURES: REGARDS DES SCIENCES HUMAINES ET SOCIALES, 2010. Actes du... [S. I.: s. n.], 2010. En ligne: http://www.enfanceetcul- tures.culture.gouv.fr/actes/ dagiral_tessier.pdf. Consulté le: 22 sept. 2014.

DE GRAAF, N. D.; DE GRAAF, P. M.; KRAAYKAMP, G. Parental cultural capital and educational attainment in the Netherlands: a refinement of the cultural capital perspective. Sociology of Education, v. 73, p. 92-111, 2000.

DIMAGGI0, P. Cultural capital and school success. American Sociological Review, v. 47, n. 2, p. 189-201, 1982.

DIMAGGI0, P. Comment on John Goldthorpe. Sociologica, v. 1, n. 2, p. 1-7, 2007.

DONNAT, O. Les Français face à la culture: de l'exclusion à l'éclectisme. Paris: La Découverte, 1994.

DRAELANTS, H. Des héritiers aux initiés? Note sur les nouvelles modalités de la reproduction sociale par l'école. Social Science Information/Informations sur les Sciences Sociales, v. 53, n. 3, p. 403-432, 2014.

DUBET, F. Le déclin de l'institution. Paris: Seuil, 2002.

DURU-BELLAT, M. Le développement cognitif, un objet sociologique?. In: DURU-BEL-LAT, M; FOURNIER, M. (dir.). L'intelligence de l'enfant: I'empreinte du social. Auxerre: Sciences Humaines, 2007. p. 165-175.

ELOY, F. Esthétisation du populaire, popularisation du savant: les stratégies d'utilisation de la culture juvénile dans le cadre du cours d'éducation musicale au collège. In: COLLOQUE ENFANCE ET CULTURES: REGARDS DES SCIENCES HUMAINES ET SOCIALES, 2010. Actes du... [S. I: s. n.], 2010. En ligne: http://www.enfanceetcultures.culture.gouv. fr/actes/eloy.pdf. Consulté le: 14 nov. 2013.

ELOY, F.; PALHETA, U. Cultures juvéniles et enseignement musical au collège. Revue Française de Pédagogie, n. 163, p. 39-50, 2008.

FABIANI, J.-L. Après la culture légitime: objets, publics, autorités. Paris: L’Harmattan, 2007.

FABIANI, J.-L. Distinction, légitimité et classe sociale. In: COULANGEON, P.; DUVAL, J. (dir.). Trente ans après la distinction. Paris: La Découverte, 2013. p. 69-82.

FARKAS, G. Cognitive skills and noncognitive traits and behaviors in stratification processes. Annual Review of Sociology, v. 29, p. 541-562, 2003.

FELOUZIS, G.; PERROTON, J. Grandir entre pairs: ségrégation ethnique et reproduction sociale dans le système éducatif français. Actes de la Recherche en Sciences Sociales, n. 180, p. 92-100, 2010.

GLASMAN, D. L'accompagnement scolaire: sociologie d'une marge de l'école. Paris: PUF, 2001.

GOLDTHORPE, J. H. "Cultural Capital”. Some critical observations. Sociologica, v. 1, n. 2, p. 1-23, 2007.

GOMBERT, P.; VAN ZANTEN, A. Le modèle éducatif du pôle "privé" des classes moyennes : ancrage et traduction dans la banlieue parisienne. Éducation et Sociétés, n. 14, p. 67-83, 2004.

GRIPSRUD, J.; HOVDEN, J. F.; MOE, H. Changing relations: class, education and cultural capital. Poetics, v. 39, n. 6, p. 507-529, 2011. 
HAYDEN, M. Introduction to international education: international schools and their communities. London: Sage, 2006.

HENRI-PANABIÈRE, G. Élèves en difficultés de parents fortement diplômés: une mise à l'épreuve empirique de la notion de transmission culturelle. Sociologie, v. 1, n. 4, p. 457-478, 2010.

HÉRAN, F. École publique, école privée: qui peut choisir? Économie et Statistique, n. 293, p. 17-39, 1996.

JACQUET-FRANCILLON, F. Culture scolaire. In: VAN ZANTEN, A. (dir.). Dictionnaire de l'éducation. Paris: PUF, 2008. p. 98-102.

JOURDAIN, A.; NAULIN, S. Héritage et transmission dans la sociologie de Pierre Bourdieu. Idées Économiques et Sociales, n. 166, p. 6-14, 2011.

KAKPO, S. Lire pour l'école à la maison: ees ressources familiales inappropriées. In: RAYOU, P. (dir.). Faire ses devoirs: enjeux cognitifs et sociaux d'une pratique ordinaire. Rennes: Presses Universitaires de Rennes, 2009. p. 127-146.

KINGSTON, P. The unfulfilled promise of cultural capital theory. Sociology of Education, v. 74, p. 88-99, 2001. Current of thought: Sociology of education at the Dawn of the 21 st Century.

LAHIRE, B. Dans les plis singuliers du social: individus, institutions, socialisation. Paris: La Découverte, 2013.

LAHIRE, B. La culture des individus: dissonances culturelles et distinctions de soi. Paris: La Découverte, 2004.

LAHIRE, B. La sociologie, la didactique et leurs domaines scientifiques. Éducation et Didactique, v. 1, n. 1, 2007. En ligne: http://educationdidactique.revues.org/86. Consulté le: 22 mai 2013.

LAHIRE, B. L'homme pluriel: les ressorts de l'action. Paris: Nathan, 1998.

LAHIRE, B. Tableaux de familles: heurs et malheurs scolaires en milieux populaires. Paris: Seuil: Gallimard, 1995.

LAMONT, M. La morale et l'argent: les valeurs des cadres en France et aux États-Unis. Paris: Métailié, 1995.

LAMONT, M.; LAREAU, A. Cultural capital: allusions, gaps and glissandos in recent theoretical developments. Sociological Theory, v. 6, n. 2, p. 153-168, 1988.

LAREAU, A.; WEININGER, E. B. Cultural capital in educational research: a critical assessment. Theory and Society, v. 32, n. 5/6, p. 567-606, 2003.

LE PAPE, M.-C.; VAN ZANTEN A. Les pratiques éducatives des familles. In: DURU-BEL-LAT, M.; VAN ZANTEN, A. Sociologie du système éducatif. Paris: PUF, 2009. p. 185-205.

LÉVY, J. Le tournant géographique: penser l'espace pour lire le monde. Paris: Belin, 1999.

MAROY, C. Le modèle du praticien réflexif à l'épreuve de l'enquête. Les Cahiers de Recherche du Girsef, n. 12, 2001.

MCDONOUGH, P. M. Choosing colleges: how social class and schools structure opportunity. Albany: State University of New York Press, 1997.

MURPHY-LEJEUNE, E. Student mobility and narrative in Europe: the new strangers. Londres: Routledge, 2002.

NASH, R. Sociologie et intelligence: pourquoi une telle ambivalence?. In: DURU-BELLAT, M.; FOURNIER, M. (dir.). L'intelligence de l'enfant: l'empreinte du social. Auxerre: Sciences Humaines, 2007. p. 151-165.

NÉTUMIÈRES, F. Méthodes de régression et analyse factorielle. Histoire et Mesure, v. 12, n. 3-4, p. 271-298, 1997. 
NEVEU, É. Les sciences sociales doivent-elles accumuler les capitaux?. Revue Française de Science Politique, v. 63, n. 2, p. 337-358, 2013.

NOGUEIRA, M. A. Capital culturel. In: VAN ZANTEN, A. (dir.). Dictionnaire de l'éducation. Paris: PUF, 2008. p. 39-41. OBERTI, M. L'école dans la ville: ségrégation, mixité, carte scolaire. Paris: Presses de Sciences Po, 2007.

OCTOBRE, S. et al. L'enfance des Ioisirs. Paris: Ministère de la Culture et de la Communication, 2010.

OLLER, A.-C. Le coaching scolaire face aux nouvelles injonctions scolaires. Sociologies Pratiques, n. 25, p. 85-97, 2012.

ORFEUIL, J.-P. (dir.). Transports, pauvretés, exclusions: pouvoir bouger pour s'en sortir. La Tour d'Aigues: L'Aube, 2004.

PAILHÉ, A.; SOLAZ, A. (dir.). Entre famille et travail: des arrangements de couple aux pra-tiques des employeurs. Paris: La Découverte, 2009.

PAINO, M.; RENZULLI, L. A. Digital dimension of cultural capital: the (in)visible advantages for students who exhibit computer skills. Sociology of Education, v. 86, n. 2, p. 124-138, 2013.

PASQUIER, D. La culture des lycéens. Paris: Autrement, 2005.

PASSERON, J.-C. Le raisonnement sociologique. Paris: Nathan, 1991.

PETERSON, R. A. Understanding audience segmentation: from elite and mass to omni-vore and univore. Poetics, v. 21, p. 243-258, 1992.

PETITAT, A. Notes critiques à propos de La reproduction de P. Bourdieu et J.-C. Passe-ron. Cahiers Vilfredo Pareto, v. 9, n. 25, p. $185-197,1971$.

PETITAT, A. Production de l'école. Production de la société: analyse sociohistorique de quelques moments décisifs de l'évolution scolaire en Occident. Genève; Paris: Droz, 1982.

PRIEUR, A.; SAVAGE, M. Emerging forms of cultural capital. European Societies, v. 15, n. 2, p. 246-267, 2013.

REAY, D. (Education and cultural capital: the implications of changing trends in education policies. Cultural Trends, v. 13, n. 2, p. 73-86, 2004.

RENARD, F. Reproduction des habitudes" et déclinaisons de l'héritage: les loisirs cultu-rels des élèves de troisième. Sociologie, v. 4, p. 413-430, 2013.

ROBBINS, D. The origins, early development and status of Bourdieu's concept of cultural capital. British Journal of Sociology, v. 56, n. 1, p. 13-30, 2005.

ROKSA, J.; POTTER, D. Parenting and academic achievement: intergenerational trans-mission of educational advantage. Sociology of Education, v. 84, n. 4, p. 299-321, 2011.

ROSA, A. Accélération: une critique sociale du temps. Paris: La Découverte, 2013.

SANSELME, F. Familles populaires et "choix" de l'établissement scolaire: les raisons des plus "faibles". Cahiers de la Recherche sur L'éducation et les Savoirs, n. 8, p. 69-93, 2009.

SIROUX, J.-L. La fabrication des élites: langage et socialisation scolaire. Louvain-la-Neuve: Academia, 2011.

SKLAIR, L. The transnational capitalist class. Oxford: Blackwell, 2001. 
SULLIVAN, A. Cultural capital and educational attainment. Sociology, v. 35, n. 4, p. 893-912, 2001.

THÉLOT, C. L'origine sociale des enseignants. Éducation \& Formations, n. 37, p. 19-21, 1994.

THÉLOT, C.; VALLET, L.-A. La réduction des inégalités sociales devant l'école depuis le début du siècle. Économie et Statistique, n. 334, p. 3-32, 2000.

VALLET, L.-A. Sur l'analyse de régression en sociologie. JOUR-NÉES DE STATISTIQUE, 39., 2007. Communication aux... [S. I.]: Société Française de Statistique à Angers, 2007.

VALLET, L.-A.; DEGENNE, A. L'origine sociale des enseignants par sexe et niveau d'enseignement: évolution entre 1964 et 1997. Éducation \& Formations, n. 56, p. 33-40, 2000.

VAN ZANTEN, A. Choisir son école. Paris: PUF, 2009a.

VAN ZANTEN, A. L'école de la périphérie. Paris: PUF, 2001.

VAN ZANTEN, A. Le travail éducatif parental dans les classes moyennes et supérieures: deux modes contrastés d'encadrement des pratiques et des choix des enfants. Informations Sociales, n. 154, p. 80-87, 2009b.

VERMANDELE, C. et al. Réussir à l'université: l'influence persistante du capital culturel de la famille. Les Cahiers de Recherche du Girsef, n. 87, 2012.

VINCENT, C. The sociology of mothering. In: APPLE, M. W; BALL, S. J.; GANDIN, L. A. (dir.). The Routledge international handbook of the sociology of education. London; New York: Routledge, 2010.

WAGNER, A.-C. Les nouvelles élites de la mondialisation: une immigration dorée en France. Paris: PUF, 1998.

WAGNER, A.-C. Les classes sociales dans la mondialisation. Paris: La Découverte, 2007.

ZAKHARTCHOUK, J.-M. L'enseignant, un passeur culturel. Paris: ESF, 1999.

ZIMDARS, A; SULLIVAN, A.; HEATH, A. Elite higher education admissions in the arts and sciences: is cultural capital the key? Sociology, v. 43, p. 648-666, 2009. 